\title{
Anti-GM1 Antibodies Cause Complement-Mediated Disruption of Sodium Channel Clusters in Peripheral Motor Nerve Fibers
}

\author{
Keiichiro Susuki, ${ }^{1,2}$ Matthew N. Rasband, ${ }^{2}$ Koujiro Tohyama, ${ }^{3}$ Katsura Koibuchi, ${ }^{1}$ Saori Okamoto, ${ }^{1}$ Kei Funakoshi, ${ }^{1}$ \\ Koichi Hirata, ${ }^{1}$ Hiroko Baba, ${ }^{4}$ and Nobuhiro Yuki ${ }^{1}$ \\ ${ }^{1}$ Department of Neurology and Research Institute for Neuroimmunological Diseases, Dokkyo Medical University School of Medicine, Tochigi 321-0293, \\ Japan, ${ }^{2}$ Department of Neuroscience, University of Connecticut Health Center, Farmington, Connecticut 06030, ${ }^{3}$ The Center for Electron Microscopy and \\ Bio-Imaging Research, Laboratory for Nano-Neuroanatomy, Iwate Medical University, Morioka 020-8505, Japan, and ${ }^{4}$ Department of Molecular \\ Neurobiology, School of Pharmacy, Tokyo University of Pharmacy and Life Sciences, Hachioji 192-0392, Japan
}

\begin{abstract}
Voltage-gated $\mathrm{Na}^{+}\left(\mathrm{Na}_{\mathrm{v}}\right)$ channels are highly concentrated at nodes of Ranvier in myelinated axons and facilitate rapid action potential conduction. Autoantibodies to gangliosides such as GM1 have been proposed to disrupt nodal Nav channels and lead to Guillain-Barré syndrome, an autoimmune neuropathy characterized by acute limb weakness. To test this hypothesis, we examined the molecular organization of nodes in a disease model caused by immunization with gangliosides. At the acute phase with progressing limb weakness, $\mathrm{Na}_{\mathrm{v}}$ channel clusters were disrupted or disappeared at abnormally lengthened nodes concomitant with deposition of IgG and complement products. Paranodal axoglial junctions, the nodal cytoskeleton, and Schwann cell microvilli, all of which stabilize $\mathrm{Na}_{\mathrm{v}}$ channel clusters, were also disrupted. The nodal molecules disappeared in lesions with complement deposition but no localization of macrophages. During recovery, complement deposition at nodes decreased, and $\mathrm{Na}_{\mathrm{v}}$ channels redistributed on both sides of affected nodes. These results suggest that $\mathrm{Na}_{\mathrm{v}}$ channel alterations occur as a consequence of complement-mediated disruption of interactions between axons and Schwann cells. Our findings support the idea that acute motor axonal neuropathy is a disease that specifically disrupts the nodes of Ranvier.
\end{abstract}

Key words: Guillain-Barré syndrome; node of Ranvier; sodium channel; ganglioside; autoantibodies; complement

\section{Introduction}

Efficient and rapid conduction of action potentials is required for signaling over the long distances between neurons and their targets. In vertebrates, this has been enabled by development of

Received July 28, 2006; revised March 4, 2007; accepted March 5, 2007.

This work was supported by a Health Sciences Research Grant (Research on Psychiatric and Neurological Diseases and Mental Health) from the Ministry of Health, Labour, and Welfare of Japan, Human Frontier Science Program (Grant RGP 38/2003 to N.Y.), in part by a grant for Hi-Tech Research from Dokkyo Medical University School of Medicine (K.H.), Ono Medical Research Foundation (N.Y.), Yokohama Foundation for Advancement of Medical Science (K.S.), Dokkyo Medical University School of Medicine, Investigator-Initiated Research Grant 2004-01-1 (K.S.), The Naito Foundation (K.S.), Kanae Foundation for Life and Socio-medical Science (K.S.), Japan Health Science Foundation (Research Resident to K.S.), Uehara Memorial Foundation (Research Fellowship to K.S.), Guillain-Barré Syndrome Foundation International (M.N.R.), and National Institutes of Health Grant NS044916 (M.N.R.). We thank the following: H. Fujita, F. Yokotsuka, M. Masubuchi, and C. Yamanaka (Dokkyo Medical University School of Medicine), K. Hales (University of Connecticut Health Center), and K. Ishida, Y. Yoshida, and T. Hanasaka (The Center for Electron Microscopy and Bio-Imaging Research, Laboratory for Nano-Neuroanatomy, Iwate Medical University) for technical assistance; D. P. Schafer (University of Connecticut Health Center), Dr. K. Matsuno [Department of Anatomy (Macro), Dokkyo Medical University School of Medicine], and Dr. S. Kuwabara (Department of Neurology, Graduate School of Medicine, Chiba University, Chiba, Japan) for meaningful discussions and suggestions; and Dr. S. J. Walsh (Center for Biostatistics, University of Connecticut Health Center) for the statistical analyses.

Correspondence should be addressed to either of the following: Keiichiro Susuki, Department of Neuroscience, University of Connecticut Health Center, 263 Farmington Avenue, Farmington, CT 06030-3401, E-mail: ksusuki@uchc.edu; or Nobuhiro Yuki, Department of Neurology and Research Institute for Neuroimmunological Diseases, Dokkyo Medical University School of Medicine, Kitakobayashi 880, Mibu, Shimotsuga, Tochigi 321-0293, Japan, E-mail:yuki@dokkyomed.ac.jp.

DOI:10.1523/JNEUROSCI.4401-06.2007

Copyright $\odot 2007$ Society for Neuroscience $\quad$ 0270-6474/07/273956-12\$15.00/0 myelin, a multilamellar membrane that ensheathes axons. The myelin sheath is interrupted at regularly spaced intervals known as the nodes of Ranvier (Poliak and Peles, 2003). These specialized axonal domains contain very high densities of voltage-gated $\mathrm{Na}^{+}\left(\mathrm{Na}_{\mathrm{v}}\right)$ channels responsible for the rapid, inward ionic currents that produce membrane depolarization. The appropriate function of nodal $\mathrm{Na}_{\mathrm{v}}$ channels is absolutely required for faithful nerve conduction, and $\mathrm{Na}_{\mathrm{v}}$ channel dysfunction in myelinated nerves may contribute to seizure, ataxia, hypersensitivity to pain (Meisler and Kearney, 2005), or generalized flaccid paralysis (Isbister and Kiernan, 2005).

Modulation of $\mathrm{Na}_{\mathrm{v}}$ channel properties by autoantibodies has been proposed as a novel mechanism in the pathophysiology of some neuroimmunological diseases (Waxman, 1995), including Guillain-Barré syndrome (GBS), a postinfectious autoimmune neuropathy characterized by acute limb weakness (Hughes and Cornblath, 2005). Histopathological findings suggest GBS is divided into two subtypes, acute inflammatory demyelinating polyneuropathy (AIDP) and acute motor axonal neuropathy (AMAN). AMAN is characterized by peripheral motor axon dysfunctions with little evidence of demyelination. Campylobacter jejuni infections often precede the onset of AMAN by 1-2 weeks and result in the development of autoantibodies against gangliosides (glycosphingolipids with sialic acids) such as GM1 and 
GD1a. Molecular mimicry between the terminal tetrasaccharide of GM1 and the lipo-oligosaccharide of $C$. jejuni is thought to cause the autoimmune attack (Yuki, 2005). Sensitization of rabbits with GM1 or the C. jejuni lipo-oligosaccharide causes acute flaccid paralysis, anti-GM1 IgG antibodies, and pathological findings identical to those of AMAN (Yuki et al., 2001, 2004; Susuki et al., 2003; Caporale et al., 2006).

In ventral roots from fatal cases of AMAN, nodes were abnormally lengthened (Griffin et al., 1996), and IgG and complement deposition was frequently present on the nodal axolemma (Hafer-Macko et al., 1996b). However, the changes in $\mathrm{Na}_{\mathrm{v}}$ channel clusters have not been evaluated. In AMAN patients with anti-ganglioside antibodies, electrophysiological studies showed prolonged refractory period of transmission, suggesting a critically reduced safety factor for impulse transmission presumably attributable to $\mathrm{Na}_{\mathrm{v}}$ channel blockade at peripheral motor nerve terminals (Kuwabara et al., 2002, 2003). Experimental results of the effect of anti-GM1 antibodies on $\mathrm{Na}_{\mathrm{v}}$ channel function are conflicting. Anti-GM1 antibodies suppressed $\mathrm{Na}^{+}$currents on isolated single myelinated rat nerve fibers in the presence of complement (Takigawa et al., 1995), although this was not confirmed by other investigators (Hirota et al., 1997). New experimental approaches are required to elucidate the contribution of antiganglioside antibody-mediated $\mathrm{Na}_{\mathrm{v}}$ channel dysfunction in the pathophysiology of AMAN. Using the AMAN rabbit model (Yuki et al., 2001; Susuki et al., 2003), here we show disruption of nodal $\mathrm{Na}_{\mathrm{v}}$ channel clusters by anti-GM1 IgG antibodies with complement deposition. Our data strongly suggest that $\mathrm{Na}_{\mathrm{v}}$ channel clusters are altered by autoimmune attack through disruption of neuron-glia interactions.

\section{Materials and Methods}

Immunization of rabbits. Male Japanese white rabbits (Kbs:JW) were obtained from Oriental Bioservice Kanto (Ibaraki, Japan). A 5 mg dose of bovine brain ganglioside mixture including GM1 was injected subcutaneously to the back at 3 week intervals until limb weakness developed as described previously (Susuki et al., 2004). As controls, we examined two rabbits injected under the same protocol with the same inoculums but without gangliosides and a normal rabbit. Two rabbits were injected under the same protocol with $1 \mathrm{mg}$ of galactocerebroside (GalC) (Sigma, St. Louis, MO) for disease control of demyelinating neuropathy model (Susuki et al., 2003). Clinical signs of immunized rabbits were carefully observed on a daily basis using a clinical scale (maximal score, 13) (Nishimoto et al., 2004) (supplemental table, available at www.jneurosci.org as supplemental material). The onset of neurological illness was defined as a daily clinical score of 4 or more. This research was approved by the Animal Care and Use Committee, Dokkyo Medical University School of Medicine (approval number 0342). Rabbits were treated according to the Guidelines for the Care and Use of Laboratory Animals of Dokkyo Medical University School of Medicine.

Anti-glycolipid antibody assays. Plasma samples obtained from paralyzed rabbits were tested for anti-GM1 IgG antibody using enzymelinked immunosorbent assay as reported previously (Yuki et al., 2001). Anti-GalC IgG antibody also was tested in plasma from GalC-sensitized rabbits. In thin-layer chromatography with immunostaining (Yuki et al., 2001), antigens used were bovine brain ganglioside mixture (same one was used for sensitization) and total gangliosides extracted from the peripheral nerves of normal Japanese white rabbits. Serum sample obtained from a patient with typical AMAN at the acute phase and monoclonal antibody (mAb) to GM1 (GB2) (Yuki et al., 2004) were used as control.

Antibodies. Fluorescein isothiocyanate-conjugated goat IgG to C3 component of rabbit complement was purchased from Nordic Immunological Laboratories (Tilburg, The Netherlands). The antibody reacts with both native and activated C3 or the fragments C3b, C3bi, and C3dg. A chicken polyclonal antibody to rabbit membrane attack complex
(MAC) was a kind gift from Dr. B. R. Lucchesi (University of Michigan Medical School, Ann Arbor, MI). The antibody was developed in conjunction with Lampire Biological Laboratories (Pipersville, PA) using rabbit C5b-9 antigen supplied by Dr. S. Bhakdi (Institute of Medical Microbiology and Hygiene, Johannes Gutenberg University, Mainz, Germany). A mouse mAb to rabbit macrophage (RAM11) was purchased from DakoCytomation (Carpinteria, CA). A mouse mAb against pan $\mathrm{Na}_{\mathrm{v}}$ channel has been described previously (Rasband et al., 1999). A guinea pig antibody to contactin-associated protein (Caspr) was a kind gift from Dr. J. Black (Yale University, New Haven, CT). Rabbit polyclonal antibody against $\beta$ IV spectrin specific domain (Berghs et al., 2000) was conjugated with Alexa Fluor 594 using a protein labeling kit (Invitrogen, Carlsbad, CA). A mouse mAb (A12/18.1) was generated against the extracellular domain of neurofascin (NF) by immunizing mice with crude membrane preparations highly enriched in NF. Antibodies specific for NF were identified by an immunostaining and Western blotting of brain membrane and cells transiently transfected by NF or neuron-gliarelated cell adhesion molecule. In rabbits, only nodal NF186 can be detected. A mouse $\mathrm{mAb}$ to moesin was purchased from Transduction Laboratories (Lexington, $\mathrm{KY}$ ). A mouse $\mathrm{mAb}$ to voltage-gated $\mathrm{K}^{+}(\mathrm{Kv}) 1.2$ was purchased from Upstate Biotechnology (Lake Placid, NY). A mouse $\mathrm{mAb}$ to neurofilament-M was purchased from Chemicon (Temecula, $\mathrm{CA}$ ). A mouse $\mathrm{mAb}$ to myelin-specific protein $2^{\prime}-3^{\prime}$-cyclic nucleotide $3^{\prime}$-phosphodiesterase (CNP) was purchased from Sigma. A mouse antiGM1 mAb (GB2) was generated as described previously (Yuki et al., 2004). Alexa Fluor 488-conjugated cholera toxin B subunit (CT-B) was purchased from Invitrogen. Fluorescent secondary antibodies used in this study were Alexa Fluor 350-, 568-, or 594-labeled goat anti-mouse IgG antibodies, Alexa Fluor 488-labeled goat anti-guinea pig IgG antibody (Invitrogen), and 7-amino-4-methylcoumarin-3-acetic acidconjugated goat anti-chicken IgG antibody (Accurate Chemical, Westbury, NY).

Immunohistochemical studies. Rabbits were anesthetized deeply with an intravenous injection of ketamine hydrochloride $(10 \mathrm{mg} / \mathrm{kg}$; Sankyo, Tokyo, Japan) and xylazine hydrochloride ( $3 \mathrm{mg} / \mathrm{kg}$; Sankyo), being repeated as needed. During the anesthesia, conduction in motor nerve fibers connected to plantar muscles was examined as described previously (Susuki et al., 2003). Then the rabbits were perfused transcardially with $2.0 \%$ paraformaldehyde in $0.1 \mathrm{M}$ phosphate buffer (PB), pH 7.4. Spinal nerve roots were excised and were cryoprotected with $30 \%$ sucrose in $0.1 \mathrm{M} \mathrm{PB}, \mathrm{pH} 7.4$, for overnight at $4^{\circ} \mathrm{C}$. The $6-\mu \mathrm{m}$-thick cryosections were permeabilized for $2 \mathrm{~h}$ in $0.1 \mathrm{M} \mathrm{PB}, \mathrm{pH} 7.4$, containing $0.3 \%$ Triton $\mathrm{X}-100$ and $10 \%$ goat serum. Sections were incubated overnight at $4^{\circ} \mathrm{C}$ with primary antibodies diluted to appropriate concentrations in the same buffer. Then the sections were thoroughly rinsed in $\mathrm{PB}$, followed by application of fluorescently labeled secondary antibodies for $45 \mathrm{~min}$ at room temperature. To detect GM1, sections were incubated overnight at $4^{\circ} \mathrm{C}$ with biotin-conjugated GB2 and then with Alexa Fluor 488conjugated streptavidin (Invitrogen) for $45 \mathrm{~min}$ at room temperature. Alexa Fluor 488-conjugated CT-B was also used. To prove that CT-B binding sites are carried by glycolipids, cryosections were pretreated with chloroform/methanol $(1: 1, \mathrm{v} / \mathrm{v})$ for $10 \mathrm{~min}$ at room temperature. IgG deposition was evaluated by the reaction of Alexa Fluor 568-conjugated antibody to rabbit IgG alone. Images were captured with a confocal laser scanning microscope TCS SP2 (Leica, Wetzlar, Germany). The immunohistochemical studies to evaluate molecular organization at nodal axons, Schwann cell microvilli, and paranodes were done as described previously (Rasband et al., 1999). Digital images were collected on Axiovert 200M fluorescence microscope fitted with ApoTome for optical sectioning (Zeiss, Thornwood, NY). For quantification, $\sim 300$ nodes in each rabbit were observed in longitudinal sections of L7 and S1 ventral roots. Nodes with complement deposition and disruption of nodal or paranodal components were also counted. For quantification of macrophage invasion, two longitudinal sections $>100 \mu \mathrm{m}$ apart in each of L6 and S1 ventral roots were immunostained with RAM11 using Vectastain ABC kit (Vector Laboratories, Burlingame, CA). They were incubated $1 \mathrm{~h}$ in diluted normal horse serum and then overnight at $4^{\circ} \mathrm{C}$ with RAM11 appropriately diluted with the same buffer. They next were incubated for $2 \mathrm{~h}$ with biotin-conjugated anti-mouse IgG antibody and then for $90 \mathrm{~min}$ 
Table 1. Features of AMAN rabbits

\begin{tabular}{|c|c|c|c|c|c|c|c|c|}
\hline \multirow[b]{2}{*}{ Rabbits } & \multicolumn{3}{|c|}{ Acute progressive phase } & \multicolumn{2}{|c|}{ Early recovery phase } & \multicolumn{3}{|c|}{ Late recovery phase } \\
\hline & $\mathrm{Bg}-16$ & $\mathrm{Bg}-17$ & $\mathrm{Bg}-18$ & $\mathrm{Bg}-19$ & $\mathrm{Bg}-20$ & $\mathrm{Bg}-21$ & $\mathrm{Bg}-22$ & $\mathrm{Bg}-23$ \\
\hline Inoculation times & 3 & 3 & 4 & 3 & 3 & 3 & 5 & 3 \\
\hline Onset of limb weakness (day) & 55 & 44 & 76 & 54 & 57 & 58 & 92 & 62 \\
\hline Days from onset to sacrifice & 2 & 2 & 3 & 13 & 15 & 28 & 38 & 38 \\
\hline Poorest clinical scale & 8 & 5 & 6 & 8 & 7 & 6 & 5 & 10 \\
\hline \multicolumn{9}{|l|}{ Anti-GM1 IgG antibody titers } \\
\hline Before immunization & 0 & 0 & 0 & 0 & 0 & 0 & 0 & 0 \\
\hline$<2$ weeks from onset & 64,000 & 64,000 & 64,000 & 32,000 & 64,000 & 64,000 & 32,000 & 64,000 \\
\hline $4-6$ weeks from onset & & & & & & 32,000 & 32,000 & 8000 \\
\hline
\end{tabular}

Blanks, Samples not available.

in a solution of avidin-biotin-horseradish peroxidase complex at room temperature. The sections were incubated for $5 \mathrm{~min}$ in a solution of $50 \mathrm{~mm}$ Tris-hydrochloric acid buffer, $\mathrm{pH}$ 7.4, containing $0.02 \% 3,3^{\prime}$ - diaminobenzidine tetrahydrochloride and $0.006 \%$ hydrogen peroxide at room temperature. The reaction was terminated by washing the slides with PBS. Images were captured using light microscope, and staining area per field was measured in at least 40 images from each AMAN rabbit using MacSCOPE (Mitani Corporation, Fukui, Japan). The quantification of macrophages was observer blinded.

Morphological analyses. Rabbits were perfused transcardially with $2.5 \%$ glutaraldehyde and $2.0 \%$ paraformaldehyde in $0.05 \mathrm{~m}$ cacodylate buffer, $\mathrm{pH} 7.4$, and the ventral roots were excised. For analysis of rabbit $\mathrm{Bg}-20$, after transcardial perfusion of $2.0 \%$ paraformaldehyde in $0.1 \mathrm{M} \mathrm{PB}$, ventral root specimens were immersed to $2.5 \%$ glutaraldehyde and $2.0 \%$ paraformaldehyde in $0.05 \mathrm{~m}$ cacodylate buffer, $\mathrm{pH}$ 7.4. Tissues were postfixed in $1 \%$ osmium tetroxide solution in $0.1 \mathrm{M}$ cacodylate buffer, $\mathrm{pH}$ 7.4 , for $2 \mathrm{~h}$ at $4^{\circ} \mathrm{C}$. After washing, they were dehydrated through a graded ethanol series and embedded in Epon 812. Semithin sections (0.5 $\mu \mathrm{m})$ were stained by toluidine blue and observed in the light microscope. Ultrathin sections were cut with a diamond knife on an ultrotome (EM UC6; Leica, Vienna, Austria). Sections were observed in an electron microscope (H-7100 or H-7650; Hitachi, Tokyo, Japan) after staining with uranyl acetate and lead citrate.

Statistical analyses. The tests are based on fitting models using the generalized estimating equation approach (Liang and Zeger, 1986). For the analyses in Figures $2 F$ and $3, B$ and $C$, the models used a "logit" link function and assumed Bernoulli variance. For the analysis in Figure 7D, the model used an "identity" link function and assumed Gaussian variance. Post hoc tests for pairwise comparisons were performed when global tests reached significance at the $5 \%$ level $(p<0.05)$. The Bonferroni's correction (Costigan, 1998) was applied to pairwise tests: a difference was considered significant when the $p$ value was $<0.0167(0.05 / 3)$. Statistical analyses were performed using the Stata software package (version 8.0; Stata, College Station, TX) by the Center for Biostatistics at the University of Connecticut Health Center.

\section{Results}

\section{Clinical, serological, and electrophysiological findings of} AMAN rabbits

Rabbits showing flaccid paralysis by sensitization with gangliosides were killed within a few days (acute progressive phase, three rabbits), $\sim 2$ weeks (early recovery phase, two rabbits), or $>4$ weeks (late recovery phase, three rabbits) after the onset (Table 1, Fig. 1A). The rabbit Bg-19 showed apparent improvement of the muscle power in hindlimbs and general activity from the 12th day after the onset, although the clinical score (number of clinical features listed in supplemental table, available at www.jneurosci. org as supplemental material) did not change. Two additional rabbits were prepared for electron microscopy and were killed 2 and $6 \mathrm{~d}$ after the onset at the acute progressive phase. Plasma samples from all paralyzed rabbits contained high anti-GM1 IgG antibody titers within 2 weeks from neurological onset (Table 1). At the late recovery phase, the titers tended to decline but remained high. However, the titers do not necessarily correlate with the clinical symptoms in both human AMAN and our rabbit model. Anti-GM1 IgG antibody titers do not differ between rab- 

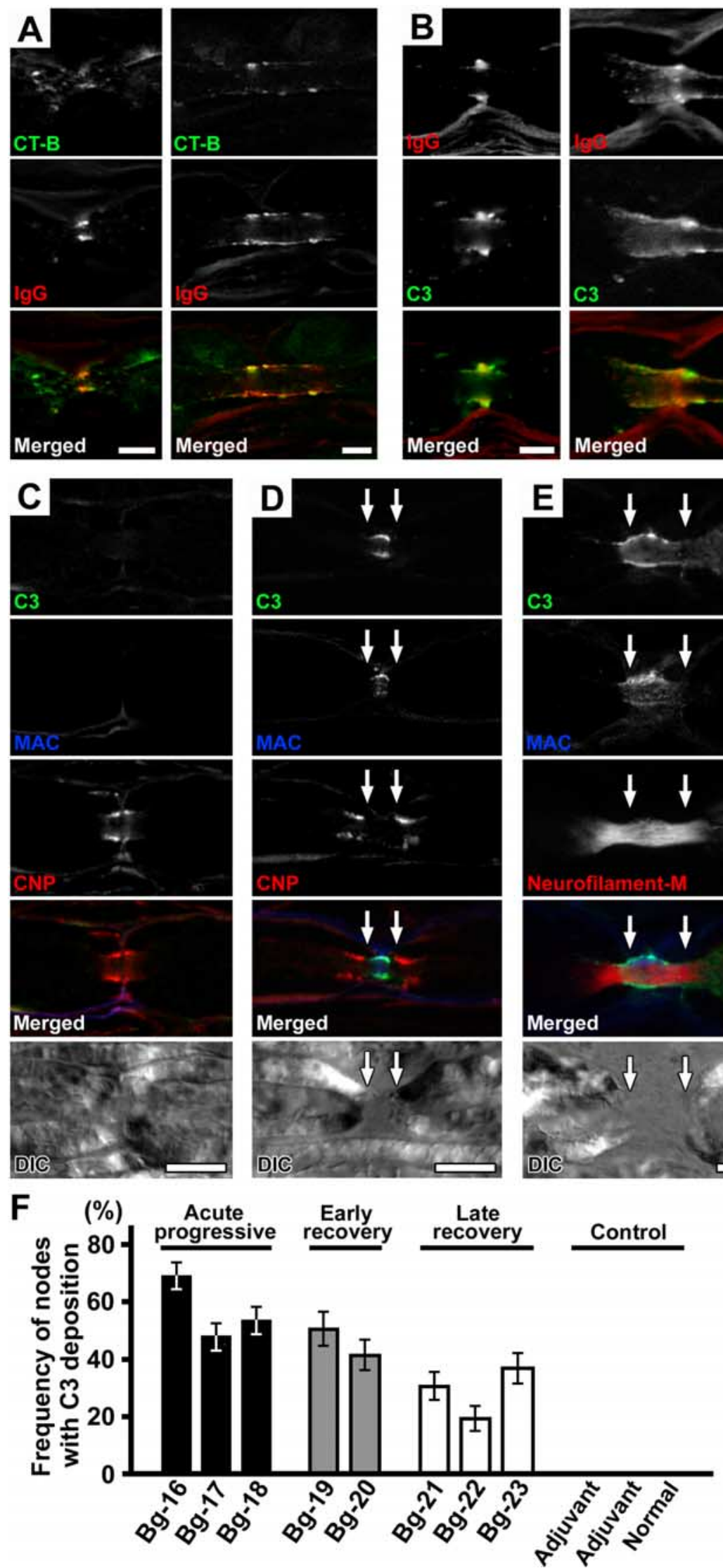

Figure 2. Lesions at nodes of Ranvier with anti-GM1 IgG and complement products in ventral roots. $\boldsymbol{A}-\boldsymbol{E}$, Immunofluorescent studies showing autoimmune lesions at nodes in longitudinal sections of ventral roots at acute progressive phase. Nerve fibers run horizontally in all panels. A, Localization of GM1 and lgG deposition. Staining of CT-B (green) colocalizes with that of rabbit $\lg G$ (red) on the nodes. Left column, In shorter lesions, the staining is mainly at nodes; right column, at longer lesions, the staining

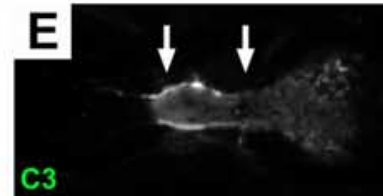

bits that develop paralysis and that do not manifest clinical findings under the same immunization protocol (van Sorge et al., 2007). Other factors such as the affinity of the antibodies may be involved in disease induction by anti-GM1 antibodies (Comín et al., 2006). Thin-layer chromatography with immunostaining confirmed the reactivity of IgG with GM1 (Fig. $1 \mathrm{~B}$ ). Plasma from the AMAN rabbits, serum from an AMAN patient, and antiGM1 mAb (GB2) reacted strongly with GM1 from both bovine brains and rabbit peripheral nerves. Consistent with our previous data of motor nerve conduction studies (Susuki et al., 2003), late components of $F$ waves were absent in two rabbits (Bg-16 and $\mathrm{Bg}-17$ ) at the acute progressive phase, whereas they were elicited normally at the recovery phase (data not shown). Compound muscle action potential amplitudes slightly decreased in rabbit Bg-23 with the most severe signs at the late recovery phase. Motor nerve conduction velocity was normal in all AMAN rabbits tested. These findings suggest the presence of motor nerve conduction failure at proximal sites at the acute phase and subsequent Wallerian-like degeneration that extended to distal parts of peripheral nerves (Susuki et al., 2003).

One of two rabbits sensitized with GalC developed limb weakness and was killed on $2 \mathrm{~d}$ after the onset. Enzyme-linked immunosorbent assay confirmed high antiGalC IgG antibody titer but negative antiGM1 IgG antibody in plasma. Electrophysiological analyses revealed motor nerve conduction slowing and decreased com-

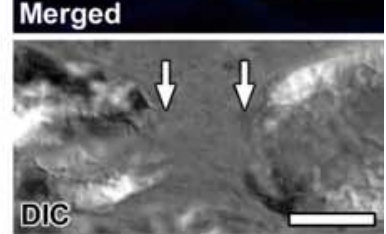

$\leftarrow$

extends toward internodes. $\boldsymbol{B}$, Complement and lg $\mathrm{G}$ deposition. Staining of the antibody to $C 3$ (green) is present at the nodes with deposition of rabbit lgG (red). Left column, In shorter lesions, the staining is mainly at nodes; right column, at longer lesions, the staining extends toward internodes. $\boldsymbol{C}$, C3 (green), MAC (blue), and CNP (red) staining in control ventral root. Neither $C 3$ nor MAC is detected at node. CNP is present at paranodal myelin. $\boldsymbol{D}$, Formation of $\mathrm{C} 3$ and $M A C$ at lengthened nodal gap. Myelin shown with CNP staining in red or differential interference contrast image is retracted from the node. Both C3 (green) and MAC (blue) staining is present between the ends of two adjacent myelin indicated by arrows. $\boldsymbol{E}$, Formation of $\mathrm{C} 3$ and MAC at lengthened nodal gap between two adjacent paranodes (arrows). Both C3 (green) and MAC (blue) staining is present mainly on the surface of naked axon at nodes shown with immunofluorescence of neurofilament-M (red). $\boldsymbol{F}$, Frequency of nodes with $\mathrm{C} 3$ deposition per total nodes in ventral roots. Affected nodes are frequently present at the acute progressive phase and lessen during recovery phase. C3 deposition is never found in control rabbits. Error bars indicate $95 \%$ confidence interval. DIC, Differential interference contrast image. Scale bars: $\boldsymbol{A}, \boldsymbol{B}, 5$ $\mu \mathrm{m} ; \boldsymbol{C}-\boldsymbol{E}, 10 \mu \mathrm{m}$. 
pound muscle action potential amplitudes, indicative of demyelinating neuropathy.

\section{Autoimmune lesions at nodal axons in ventral roots}

The earliest pathological change in human AMAN is lengthening of nodes in ventral roots (Griffin et al., 1996). Similarly, in L7 ventral roots from two AMAN rabbits at the acute progressive phase, 25 of 52 nodes (48\%) were clearly widened under the light microscope compared with the nodes from control rabbit, in particular the paranodal myelin was retracted leaving naked axon. Close examination of lengthened nodes at the electron microscopic level showed disrupted nodal or paranodal structures, including Schwann cell cytoplasm and microvilli (Fig. 1C,D). Paranodal myelin was distorted with small amounts of myelin debris. Some paranodal loops were detached from the axolemma (Fig. 1E).

We previously showed IgG deposition at nodes and axons in the cauda equina (Susuki et al., 2003). To test the idea that the autoantibodies bind to GM1, we first determined the presence of GM1 in these lesions. In ventral roots from the AMAN rabbits at the acute progressive phase, anti-GM1 mAb (GB2) or CT-B stained nodes (Fig. 2A) and axons (supplemental Fig. $1 \mathrm{~A}$, available at www.jneurosci.org as supplemental material) with IgG deposition. CT-B staining disappeared during pretreatment of cryosections with chloroform and methanol to extract all glycolipids including gangliosides, suggesting that the stained molecule is GM1 itself and not another glycoprotein bearing the GM1 epitope (data not shown). These findings suggest that the IgG binds to GM1 at nodes and axons. Consistent with this, GM1 epitope was detected at nodal and paranodal axolemma by immunoelectron microscopy (Sheikh et al., 1999). In contrast, there was no or minimal staining of GB2 or CT-B in preserved axons without IgG deposition (supplemental Fig. $1 A$, asterisks, available at www.jneurosci.org as supplemental material). In control rabbits, we found GB2 stained paranodal myelin, but minimal at nodes (supplemental Fig. 2, available at www.jneurosci.org as supplemental material), similar to previous reports (Molander et al., 1997; Sheikh et al., 1999). In normal nerve fibers, the GM1 epitope may be masked, and autoimmune destruction may be necessary for them to be exposed and allow primary antibody access in immunohistochemistry. Alternatively, GM1 epitope may be lost during the usual immunohistochemical procedures, whereas autoantibodies to GM1 as seen in AMAN may cause them to be stabilized and fixed at the nodes. However, the possibility that GM1 is abnormally localized to the affected nodes or axons cannot be excluded.

We next examined depositions of IgG and C3, the intermediate component of rabbit complement, on ventral roots at the acute progressive phase to show complement-mediated autoimmune attack on nodes and axons. C3 staining was present at the nodes with deposition of IgG (Fig. $2 B$ ). Axons were also labeled with both IgG and C3 (supplemental Fig. $1 B$, available at www. jneurosci.org as supplemental material). These immunohistochemical findings are identical to those in human AMAN, suggesting that autoimmune attack occurs first at nodes and then extends to internodal axons (Hafer-Macko et al., 1996b). C3 deposition was never seen in control rabbits (Fig. 2C), and we did not detect nodal C3 staining in ventral roots from a GalC-sensitized rabbit with demyelinating neuropathy (data not shown). In human AMAN, the disease is usually restricted to peripheral motor nerve fibers, but some patients show sensory nerve involvements as well (Hughes and Cornblath, 2005). Similarly, in a few rabbits sensitized with gangliosides, both motor and sensory nerves are involved (K.S., unpublished observation), but none of the rabbits examined in the present study showed C3 deposition in S1 dorsal roots (data not shown).

Complement can be activated via the classical, alternative, or lectin pathways and culminates in the incorporation of lytic MAC. Some nodes were stained for MAC in human AMAN (Hafer-Macko et al., 1996b). To further implicate the complement-mediated action of anti-GM1 antibodies at the nodes, we examined formation of MAC, the final product of complement activation, in AMAN rabbit nerves. At the acute phase, most nodes with $\mathrm{C} 3$ deposition also showed MAC staining (Fig. 2D,E). When we quantified the frequency of the nodal lesions from a total of 1050 nodes observed in ventral roots from three rabbits at the acute progressive phase, 478 nodes $(45.5 \%)$ had both C3 and MAC staining, 75 (7.1\%) had C3 but no MAC staining, and none had MAC but no C3 staining. MAC staining never appeared at nodes in control rabbits (Fig. 2C). To examine the primary lesion of autoimmune attack, we also immunostained the ventral roots with antibodies to CNP, a marker of Schwann cells, or neurofilament-M, a marker of axons. In the apparently lengthened nodes, both $\mathrm{C} 3$ and MAC staining was present between the end of two adjacent paranodes (Fig. 2D) and predominantly on the surface of the naked axons (Fig. $2 E$ ). These immunohistochemical results together with electron microscopy showing lengthened nodes (Fig. 1C) suggest that the complement-mediated autoimmune attack by anti-GM1 IgG antibodies mainly occurs at nodal axolemma, not myelinating Schwann cells.

We next examined the changes in nodal lesions with complement deposition throughout the clinical course (Fig. $2 F$ ). Nodes with $\mathrm{C} 3$ deposition were predominantly seen at the acute progressive phase and decreased significantly at the late recovery phase, supporting the pathogenic role of complement on the initial nodal disruption. For the statistical analyses to compare the three groups, acute progressive, early recovery, and late recovery phases, the $p$ value from the global test was $<0.001$. The results for pairwise comparisons were as follows: acute progressive versus late recovery phases, $p<0.001$; acute progressive versus early recovery phases, $p=0.14$; early recovery versus late recovery phases, $p=0.017$.

\section{Disruption of $\mathrm{Na}_{\mathrm{v}}$ channel clusters and related molecules at nodal axons}

Next we focused on the change in $\mathrm{Na}_{\mathrm{v}}$ channel clusters at the acute progressive phase. $\mathrm{Na}_{\mathrm{v}}$ channel localization was altered or disappeared at lengthened nodes with $\mathrm{C} 3$ or MAC deposition (Fig. 3A). As the nodal C3 deposition extends, the frequency of disrupted $\mathrm{Na}_{\mathrm{v}}$ channel immunoreactivity at the affected nodes significantly increased (Fig. $3 B$ ). The frequency of disrupted $\mathrm{Na}_{\mathrm{v}}$ channel staining was significantly greater in nodes with MAC deposition than in nodes without MAC staining in AMAN rabbits or in nodes from control rabbits (Fig. $3 C$ ). These findings suggest that MAC produced via complement-mediated action of anti-GM1 IgG antibodies first appears at the nodal axolemma, then extends toward the internodes, and disrupts $\mathrm{Na}_{\mathrm{v}}$ channel clusters.

To further elucidate how autoimmune attack disrupts $\mathrm{Na}_{\mathrm{v}}$ channel clusters, we next examined the molecular organization of nodal axons in ventral roots at the acute progressive phase. The cytoskeletal proteins $\beta$ IV spectrin and ankyrin $\mathrm{G}$ link $\mathrm{Na}_{\mathrm{v}}$ channels and NF186 to the actin-based cytoskeleton (Berghs et al., 2000; Komada and Soriano, 2002; Lacas-Gervais et al., 2004; Yang et al., 2004; Sherman et al., 2005). In control rabbits, $\mathrm{Na}_{\mathrm{v}}$ 

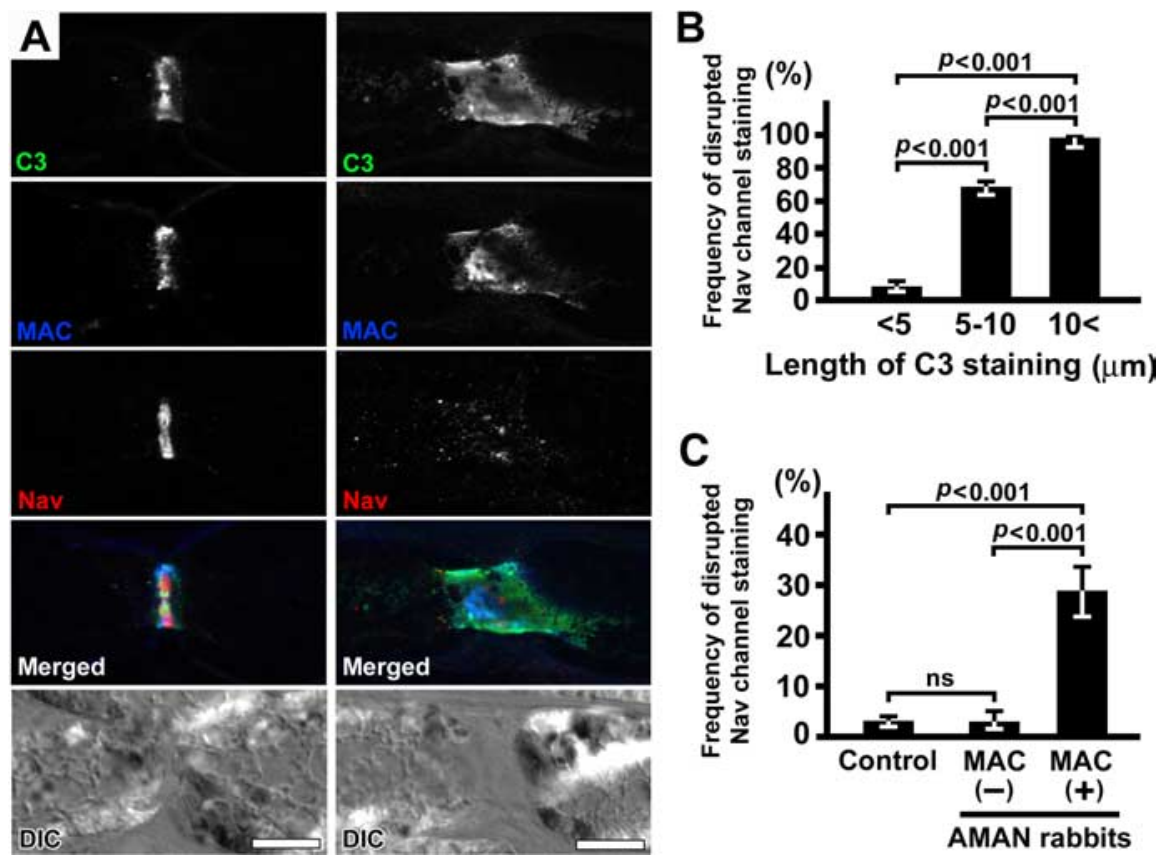

Figure 3. Lesions at nodes of Ranvier with complement deposition and disrupted $\mathrm{Na}_{v}$ channel clusters. $\boldsymbol{A}$, Disruption of $\mathrm{Na}_{v}$ channel clusters at the acute progressive phase. Both $\mathrm{C} 3$ (green) and MAC (blue) staining is present at nodes. Clusters of $\mathrm{Na}_{v}$ channels (red) are preserved at lesions restricted to the node (left column), whereas $\mathrm{Na}_{v}$ channels almost disappear at lengthened nodes with extended $(3$ and MAC staining (right column). Nerve fibers run horizontally in both columns. $\boldsymbol{B}$, Relationship between $\mathrm{Na}_{\mathrm{v}}$ channel cluster disruption and length of complement deposition. Frequency of disrupted $\mathrm{Na}_{\mathrm{v}}$ channel immunoreactivity is shown in nodes with C 3 staining with lengths of $<5,5-10$, or $>10 \mu \mathrm{m}$. Data were collected from three AMAN rabbits at the acute progressive phase. For the statistical analyses to compare the three groups, the $p$ value from the global test was $<0.001$. A significant difference was found in each pairwise comparison $(p<0.001)$. Error bars indicate $95 \%$ confidence interval. $\boldsymbol{C}$ Relationship between $\mathrm{Na}_{v}$ channel cluster disruption and MAC deposition. Frequency of nodes with disrupted $\mathrm{Na}_{v}$ channel clusters is shown in nodes from three control rabbits, in nodes without MAC staining in three AMAN rabbits at the acute progressive phase, and in nodes with MAC deposition. A significant difference was found in the global test $(p<0.001)$. Specific pairwise comparisons shows that nodes with MAC deposition have more disruption of $\mathrm{Na}_{v}$ channel clusters than nodes without MAC staining or nodes from control rabbits $(p<0.001)$. There was no significant difference between nodes without MAC staining in AMAN rabbits and nodes from control rabbits ( $p=0.95$ ). Error bars indicate $95 \%$ confidence interval. DIC, Differential interference contrast image. Scale bars, $10 \mu \mathrm{m}$.

channels, $\beta$ IV spectrin, and NF186 were clearly detected at nodes (Fig. 4A,E). When the complement deposition was restricted to nodes, the clusters of $\mathrm{Na}_{\mathrm{v}}$ channels and $\beta \mathrm{IV}$ spectrin were preserved (69.7\% of nodes with MAC deposition) (Table 2, Fig. $4 B$ ). The disruption of $\mathrm{Na}_{\mathrm{v}}$ channel clusters was completely associated with that of $\beta$ IV spectrin (30.3\%) (Table 2). In lesions with C3 deposition extending to paranodes, clusters of $\mathrm{Na}_{\mathrm{v}}$ channels and $\beta I V$ spectrin often showed altered shape and decreased intensity (Fig. 4C). In some lesions, the staining of $\beta \mathrm{IV}$ spectrin did not colocalize with that of $\mathrm{Na}_{\mathrm{v}}$ channels (Fig. 4C), indicating the disruption of the Nav channel complex at nodes. This finding was observed in 11 of 208 (5.3\%) nodes with MAC deposition in AMAN rabbits but never in control rabbits. The intensity of C3 staining was reduced wherever $\mathrm{Na}_{\mathrm{v}}$ channel immunoreactivity was retained (Fig. $4 C$, arrows). Lesions with more extended C3 were devoid of $\mathrm{Na}_{\mathrm{v}}$ channels and $\beta$ IV spectrin (Fig. 4D). A similar pattern of disrupted NF186 clusters was observed in ventral roots from AMAN rabbits (Fig. $4 F-H$ ). These results demonstrate that anti-GM1 antibody-mediated autoimmune attack disrupts the molecular architecture of nodal axons, including loss of $\mathrm{Na}_{\mathrm{v}}$ channels.

\section{Disruption of Schwann cell microvilli}

C3 or MAC staining was occasionally detected in the space surrounding nodes. In the peripheral nervous system,
Schwann cells form the myelin sheath and extend a collar of microvilli into the nodal gap. $\mathrm{Na}_{\mathrm{v}}$ channel clustering requires contact from these Schwann cell microvilli, in which a cell adhesion molecule called gliomedin binds NF186 and initiates node formation (Eshed et al., 2005). These microvilli may play important roles in stabilizing nodal membrane domains (Yang et al., 2004). In human AMAN, Schwann cell microvilli were displaced at the lengthened nodes (Griffin et al., 1996). To investigate whether altered Schwann cell microvilli might contribute to nodal disruption, we analyzed the immunoreactivity of moesin, another protein enriched in microvilli (Scherer et al., 2001) (Fig. 5A), in ventral roots at the acute progressive phase. In lesions with autoimmune attack restricted to the nodal area, MAC staining partially colocalized with moesin immunoreactivity (Fig. 5B). Similar to the axonal molecules at nodes, moesin localization was also disrupted or not present at affected nodes with extended MAC deposition (19.0\% of nodes with MAC deposition) (Table 2, Fig. 5C,D). In most nodes with MAC deposition, the disruption of moesin was associated with that of $\beta$ IV spectrin (Table 2). These findings indicate that the Schwann cell microvilli are also disrupted by autoimmune attack, although it remains unclear whether this occurs primary or secondary to disruption of the nodal axolemma.

\section{Disruption of paranodes and juxtaparanodes}

Paranodal junctions may act as a diffusion barrier for ion channel localization (Bhat et al., 2001; Rios et al., 2003). We considered the possibility that disruption of paranodal junctions might lead to alteration of nodal $\mathrm{Na}_{\mathrm{v}}$ channels, because $\mathrm{Na}_{\mathrm{v}}$ channel disruption was clearly associated with the length of complement deposition along the axons (Fig. 3B). To test this, we immunostained ventral roots at the acute progressive phase with an antibody to Caspr, a cell adhesion molecule at the paranodal axolemma that is essential for the formation of the axoglial junctions (Einheber et al., 1997; Menegoz et al., 1997; Peles et al., 1997; Bhat et al., 2001; Rios et al., 2003) (Fig. $6 A$ ). Paralyzed rabbits at the acute progressive phase showed various stages of disruption in nodes and paranodes. In lesions with MAC deposition restricted to nodes, both $\mathrm{Na}_{\mathrm{v}}$ channel and Caspr staining was preserved $(71.5 \%$ of nodes with MAC deposition) (Table 2, Fig. 6B). As MAC deposition extended to paranodes, Caspr staining was reduced or disrupted (Fig. $6 C, D) . \mathrm{Na}_{\mathrm{v}}$ channel clusters were altered coincident with disruption of Caspr immunoreactivity (22.2\%) (Table 2). Despite the altered Caspr staining, $6.3 \%$ of $\mathrm{Na}_{\mathrm{v}}$ channel clusters appeared normal (Table 2, Fig. 6C). Similar findings were never seen in control animals (Table 2). In lesions with remarkably extended MAC deposition, neither $\mathrm{Na}_{\mathrm{v}}$ channel nor Caspr staining was detected (Fig. 6E). These results demon- 
strate that axoglial junctions are also damaged by the autoimmune attack and suggest that the disruption of paranodal junctions can contribute to alteration of $\mathrm{Na}_{\mathrm{v}}$ channel clusters.

It is also possible that $\mathrm{Kv}$ channels at juxtaparanodes (Poliak and Peles, 2003) (Fig. $6 F$ ) redistribute into paranodes and contribute to the acute nerve conduction failure in AMAN. Therefore, we evaluated $\mathrm{Kv}$ channel localization in affected nerve fibers. Juxtaparanodal Kv channel staining were preserved until C3 could be detected at these sites (Fig. 6G-I). Kv channel clusters was not apparent in lesions with remarkably extended C3 deposition (Fig. 6J). These results suggest that Kv channel clusters are altered only at the most advanced stage of paranode disruption.

\section{Association of macrophages on nodal disruption}

In human AMAN, macrophages recruited by bound autoantibodies and activated complement are thought to overlie and insert processes into the nodal gap, disrupting the myelin sheath attachment sites at paranodes and entering the internodal periaxonal space (Griffin et al., 1996). Macrophages in the periaxonal space with preserved myelin have been confirmed in the spinal nerve roots from AMAN rabbits (Susuki et al., 2003; Yuki et al., 2004). To determine whether macrophages are responsible for initial disruption of nodes, we analyzed macrophage infiltration in ventral roots. Macrophages invaded ventral roots at the acute progressive phase, but most were not localized to the affected nodes with complement deposition (Fig. $7 A$ ). Furthermore, nodal molecules were disrupted at lesions with MAC deposition but no overlying macrophages. We quantified the frequency of macrophage binding at the affected nodes with disrupted $\beta \mathrm{IV}$ spectrin or Caspr clusters. Nearly $60 \%$ (34 of 59) of nodes did not show associated macrophages. Macrophages were detected at some affected nodes with complement deposition (Fig. 7B), but these cases were rare. The frequency of macrophages at affected nodes with C3 deposition was only $9.0 \%$ ( 47 of 521 at the acute progressive phase). When we examined changes in macrophage invasion over the clinical course, we found that macrophage invasion was significantly more frequent at the early recovery phase (Fig. $7 C, D)$. For the statistical analyses to compare the three groups, acute progressive, early recovery, and late recovery phases, the $p$ value from the global test was $<0.001$. The results for pairwise comparisons were as follows: acute progressive versus
Control
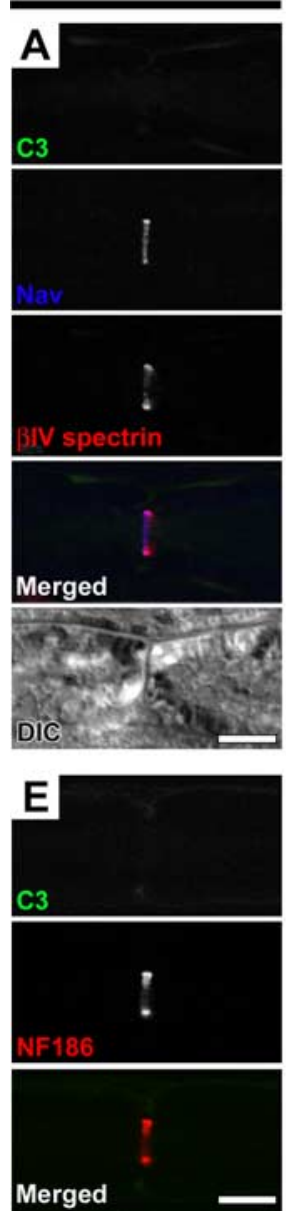
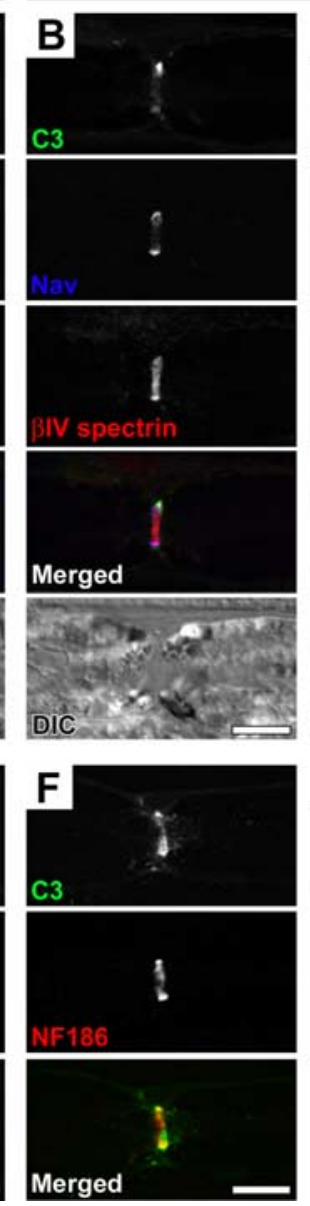

AMAN rabbits
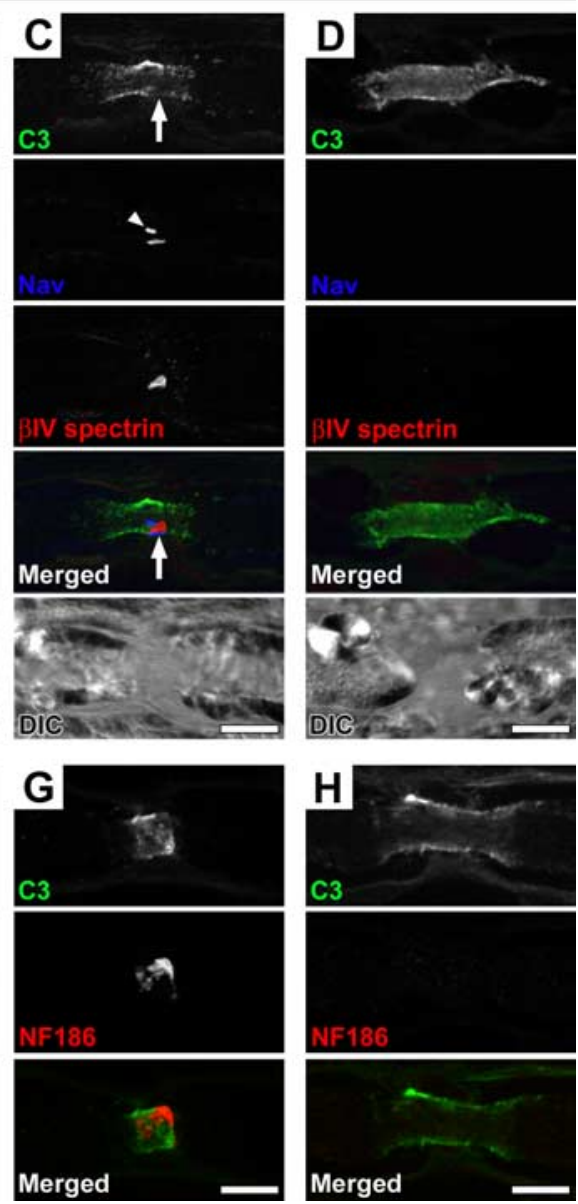
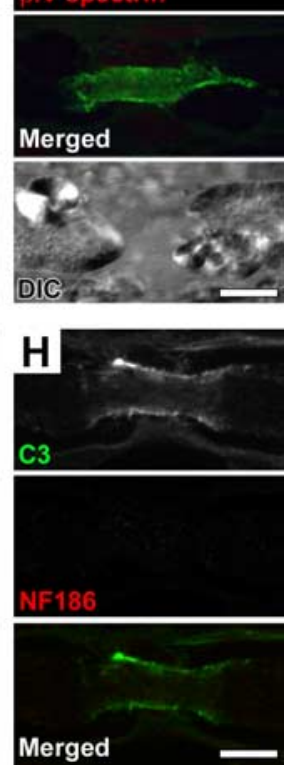

Figure 4. Alterations of $\mathrm{Na}_{v}$ channels and related molecules at nodal axons by autoimmune attack. All panels show longitudinal sections of ventral roots, and nerve fibers run horizontally. Sections are immunostained with antibodies to C 3 (green, all panels), $\mathrm{Na}_{v}$ channels (blue, $\left.\boldsymbol{A}-\boldsymbol{D}\right)$, $\beta \mathrm{IV}$ spectrin (red, $\boldsymbol{A}-\boldsymbol{D}$ ), or pan-NF (red, $\boldsymbol{E}-\boldsymbol{H}$ ). Anti-pan-NF antibody specifically stains NF186 in nodal axons. Different stages of nodal disruption in AMAN rabbits at the acute progressive phase are depicted. $\boldsymbol{A}, \boldsymbol{E}$, Staining results in the control rabbit showing the $\mathrm{Na}_{\mathrm{v}}$ channel $(\boldsymbol{A})$, $\beta \mathrm{IV}$ spectrin $(\boldsymbol{A})$, and NF186 $(\boldsymbol{E})$ clusters at the nodes. No $\mathrm{C} 3$ staining is detected. $\boldsymbol{B}, \boldsymbol{F}$, Lesions with $C 3$ staining restricted at nodes. The clusters of $\mathrm{Na}_{v}$ channels $(\boldsymbol{B}), \beta \mathrm{IV}$ spectrin $(\boldsymbol{B})$, and NF186 $(\boldsymbol{F})$ are mostly preserved and colocalize with (3 staining. $\boldsymbol{C}$, $\mathbf{G}$, Lesions with $\mathbf{C} 3$ staining extending to paranodes. The node is lengthened $(\boldsymbol{C})$, and the shapes of clusters of $\mathrm{Na}_{\mathrm{v}}$ channels $(\boldsymbol{C}), \beta \mathrm{IV}$ spectrin $(\boldsymbol{C})$, and NF186 (G) are altered. Note that the staining of $\mathrm{Na}_{\mathrm{v}}$ channels does not colocalize with that of $\beta \mathrm{IV}$ spectrin (C). There is abnormal aggregation of $\mathrm{Na}_{\mathrm{v}}$ channel staining in the middle of axon (arrowhead). At the region with remaining $\mathrm{Na}_{v}$ channel staining, signal of $\mathrm{C} 3$ is relatively weak (C, arrows). $\boldsymbol{D}, \boldsymbol{H}$, Lesions with remarkably extended $(3$ staining. The node is lengthened $(\boldsymbol{D})$, and clusters of Nav channels $(\boldsymbol{D}), \beta \mathrm{IV}$ spectrin $(\boldsymbol{D})$, and NF186 $(\boldsymbol{H})$ disappear. DIC, Differential interference contrast image. Scale bars, $10 \mu \mathrm{m}$.

Table 2. Relationship between disruptions of molecules at the affected nodes in AMAN rabbits

\begin{tabular}{|c|c|c|c|c|c|}
\hline & & \multicolumn{2}{|l|}{$\mathrm{Na}_{\mathrm{v}}$ channels } & \multicolumn{2}{|l|}{ Moesin } \\
\hline & & Normal & Disrupted & Normal & Disrupted \\
\hline \multirow[t]{2}{*}{$\beta \mathrm{IV}$ spectrin } & Normal & $69.7(97.7)$ & $0(0)$ & $76.9(93.8)$ & $2.4(1.8)$ \\
\hline & Disrupted & $0(0)$ & $30.3(2.3)$ & $1.6(2.2)$ & $19.0(2.2)$ \\
\hline \multirow[t]{2}{*}{ Caspr } & Normal & 71.5 (97.4) & $0(0.9)$ & & \\
\hline & Disrupted & $6.3(0)$ & $22.2(1.7)$ & & \\
\hline
\end{tabular}

Percentages of nodes with MAC deposition at the acute progressive phase are shown.

Data are obtained from L7 and S1 ventral roots in each rabbit by immunostaining with $\mathrm{Na}_{\mathrm{v}}$ channels and $\beta \mathrm{IV}$ spectrin $(n=208), \mathrm{Na}_{\mathrm{v}}$ channels and Caspr $(n=$ $284)$, and $\beta$ IV spectrin and moesin ( $n=247)$.

Values in parentheses are percentages of nodes from control rabbits by immunostaining with $\mathrm{Na}_{\mathrm{v}}$ channels and $\beta \mathrm{IV}$ spectrin $(n=216), \mathrm{Na}_{\mathrm{v}}$ channels and Caspr $(n=235)$, and $\beta I V$ spectrin and moesin $(n=272)$. 


\section{Control}
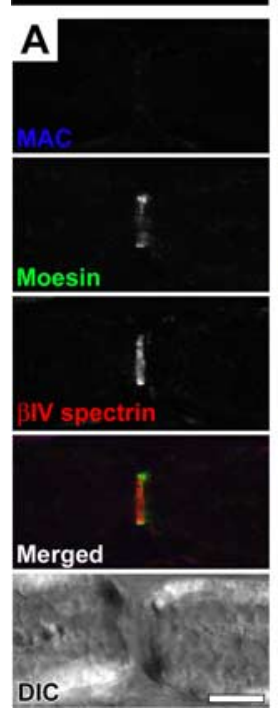

AMAN rabbits
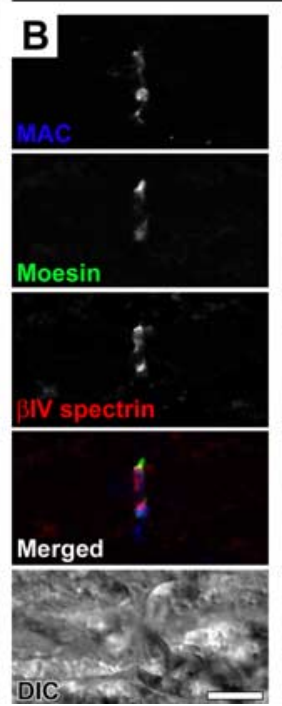
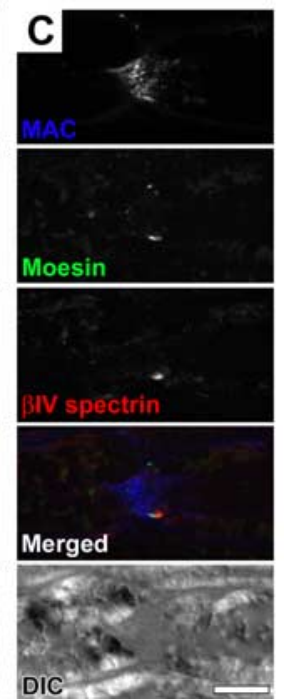
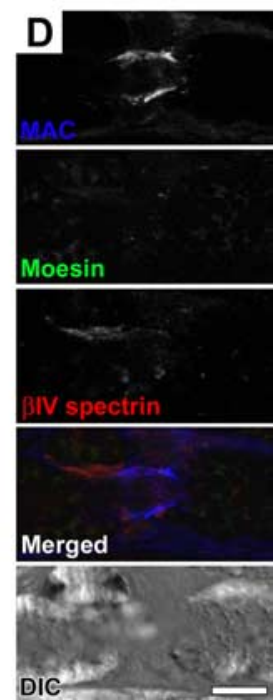

Figure 5. Alterations of Schwann cell microvilli by autoimmune attack. All panels show longitudinal sections of ventral roots, and nerve fibers run horizontally. Sections are immunostained with antibodies to MAC (blue), moesin (green), and $\beta$ IV spectrin (red). Different stages of nodal disruption in AMAN rabbits at the acute progressive phase are depicted. $\boldsymbol{A}$, Staining results in a control rabbit showing the moesin and $\beta$ IV spectrin clusters at nodes. No MAC staining is detected. $\boldsymbol{B}$, Lesions with MAC staining restricted to nodes. The clusters of moesin and $\beta$ IV spectrin are mostly preserved. MAC staining does not completely colocalize with moesin staining. $C$, Lesions with MAC staining extending to paranodes. The node is lengthened, and the shapes of clusters of moesin and $\beta$ IV spectrin are altered. $\boldsymbol{D}$, Lesions with remarkably extended MAC staining. Node is lengthened, and clusters of moesin and $\beta$ IV spectrin disappear. DIC, Differential interference contrast image. Scale bars, $10 \mu \mathrm{m}$.

\section{Control}
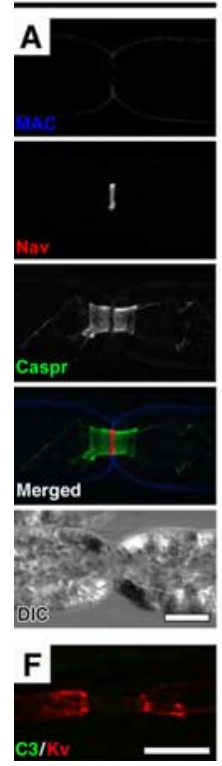
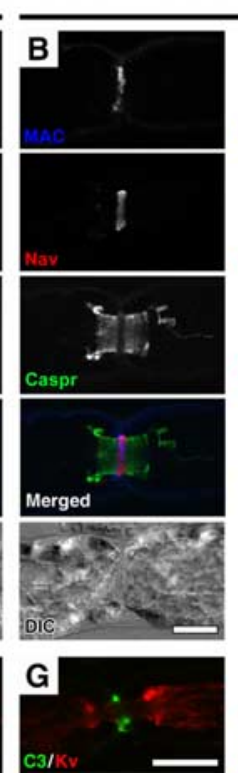

AMAN rabbits
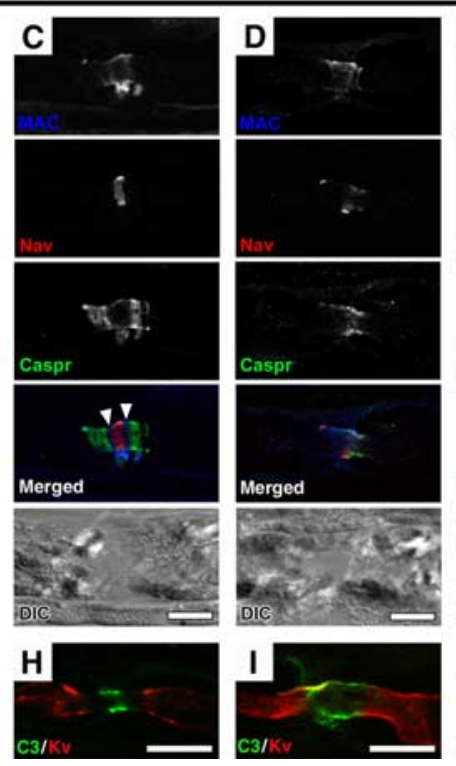

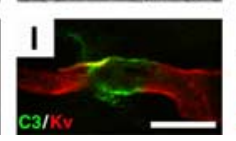

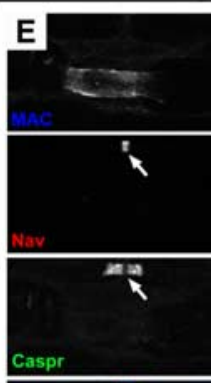
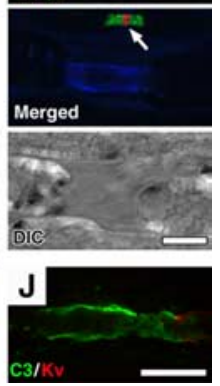

Figure 6. Alterations of $\mathrm{Na}_{v}$ channels, paranodes, and juxtaparanodes by autoimmune attack. All panels show longitudinal sections of ventral roots, and nerve fibers run horizontally. Sections are immunostained with antibodies to $M A C$ (blue), $\mathrm{Na}_{v}$ channels (red), and Caspr (green) $(\boldsymbol{A}-\boldsymbol{E})$, or (3 (green) and Kv channels (red) $(\boldsymbol{F}-\boldsymbol{J})$. Different stages of disruption in AMAN rabbits at the acute progressive phase are depicted. $\boldsymbol{A}, \boldsymbol{F}$, Staining in a control rabbit showing the $\mathrm{Na}_{\mathrm{v}}$ channel cluster at node, Caspr clusters at paranodes $(\boldsymbol{A})$, and Kv channel clusters at juxtaparanodes $(\boldsymbol{F})$. Neither MAC nor $\mathbf{C} 3$ staining is detected at node. $\boldsymbol{B}, \boldsymbol{G}$, Autoimmune lesions restricted to nodes. Clusters of $\mathrm{Na}_{\mathrm{v}}$ channels $(\boldsymbol{B})$, Caspr $(\boldsymbol{B})$, and $\mathrm{Kv}$ channels $(\boldsymbol{G})$ are not affected. $\boldsymbol{C}, \boldsymbol{H}$, Autoimmune lesions extended to paranodes. The gap between Caspr staining is lengthened more than that in normal (depicted in A) and is filled with MAC staining $(\boldsymbol{C})$. Note that the $\mathrm{Na}_{v}$ channel cluster is still preserved, and there are clear gaps between $\mathrm{Na}_{v}$ channel and Caspr clusters (arrowheads). Kv channel clusters are preserved $(\boldsymbol{H})$. $\boldsymbol{D}, \boldsymbol{I}$, Autoimmune lesions extended to juxtaparanodes. Node is lengthened, and the clusters of $\mathrm{Na}_{v}$ channels and Caspr are remarkably disrupted (D). Kv channel cluster at juxtaparanode partially colocalizes with C3 staining (yellow) (I). $\boldsymbol{E}$, J, Lesions with broadly extended MAC or C3 deposition. Node is lengthened, and the staining of both $\mathrm{Na}_{v}$ channels and Caspr completely disappears, whereas these molecules are preserved in adjacent fiber without MAC deposition ( $\boldsymbol{E}$, arrows). Kv channel staining is no longer apparent ( $\boldsymbol{J})$. DIC, Differential interference contrast image. Scale bars, $10 \mu \mathrm{m}$.
Redistribution of disrupted molecules during the recovery phase

The clinical signs of AMAN rabbits reached a maximum within 2 weeks, followed by spontaneous recovery. Ventral roots from rabbits at the early and late recovery phases had some affected nodes with redistribution of nodal or paranodal molecules. Specifically, clusters of $\mathrm{Na}_{\mathrm{v}}$ channels, $\beta$ IV spectrin, NF186, moesin, and Caspr were observed on both sides of the lengthened nodes (Fig. $8 A-D$ ). The intensity of C3 and MAC staining was reduced (Fig. $8 B, D$ ). These events are not likely to reflect an initial step in loss of nodal molecules, because they occasionally appear during recovery but rarely at acute progressive phase. The frequency of binary $\mathrm{Na}_{\mathrm{v}}$ channel clusters per total nodes observed was $0.6 \%$ (6 of 1050) at the acute progressive phase, $3.0 \%$ (17 of 565) at the early recovery phase, and $2.8 \%(26$ of 933) at the late recovery phase. Ongoing alteration and redistribution of these molecules coexisted at the early recovery phase. Kv channel staining was also observed adjacent to some lengthened nodes at the late recovery phase (data not shown). Electron microscopy at the early recovery phase showed the presence of Schwann cell microvilli as well as paranodal myelin loops at the end of the lengthened node (Fig. $8 E-H$ ). One possible interpretation of these images is that fusion of two adjacent heminodes with each other forms new nodes of Ranvier during recovery after nodal disruption.

\section{Discussion}

In a disease model identical to human AMAN, we showed the disruption of nodes of Ranvier in peripheral motor nerve fibers by anti-GM1 IgG antibodies via the complement pathway. Our results provide conclusive evidence for $\mathrm{Na}_{\mathrm{v}}$ channel disruption by anti-ganglioside antibodies in AMAN, which had been proposed previously as a new mechanism of neurological disease (Waxman, 1995). Despite remarkable limb weakness, paralyzed rabbits display relatively mild axonal degeneration in peripheral motor nerves within a few days of the onset, as in human AMAN (Griffin et al., 1996). Thus, nodal lesions could be mainly responsible for the nerve conduction failure and consequent limb weakness at the acute phase in AMAN. Disruption of nodal components is likely required for the development of clinical symptoms, because in vitro experiments suggest that the deposition of antiGM1 antibodies and complement products at nodes is not sufficient to block 

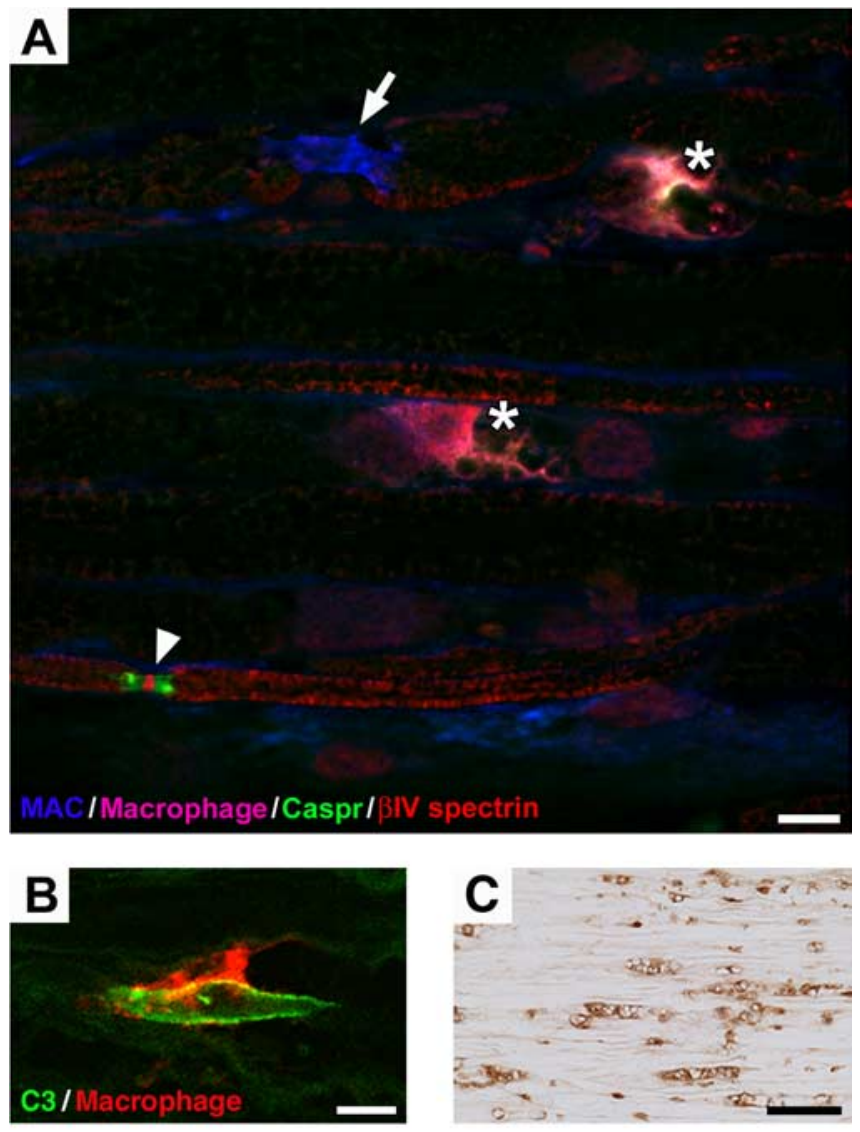

D

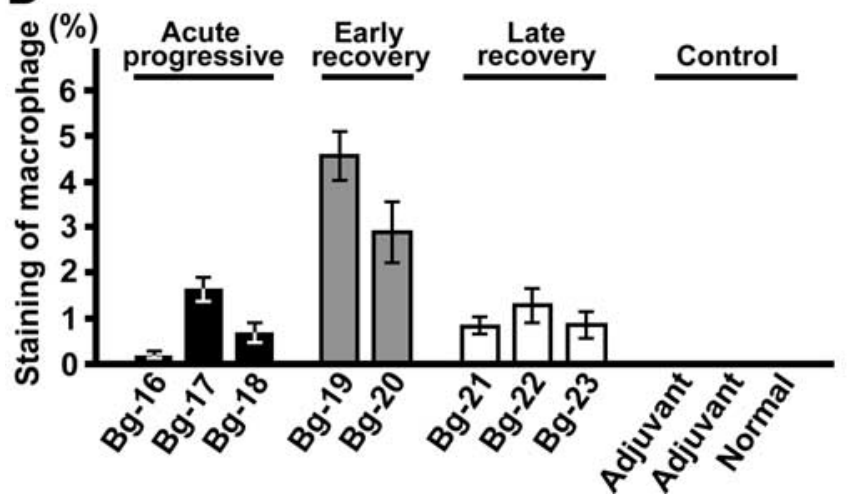

Figure 7. Macrophage invasion in ventral roots. $\boldsymbol{A}$, Longitudinal section of ventral root at the acute progressive phase stained with antibodies to MAC (blue), rabbit macrophages (pink), $\beta$ IV spectrin (red), and Caspr (green). Both $\beta$ IV spectrin and Caspr staining disappears at the node with MAC deposition (arrow), whereas these clusters are preserved at nodes without MAC deposition (arrowhead). Macrophages (asterisks) invade the ventral root, but none overlays the affected node (arrow). B, Longitudinal section of ventral root at the acute progressive phase. A macrophage (red) overlays the affected node with C3 deposition (green). C, Remarkable macrophage invasion in ventral root at the early recovery phase. $\boldsymbol{D}$, Quantification of macrophage invasions in rabbit ventral roots. The area of macrophage staining per field (illustrative finding is depicted in $\boldsymbol{C}$ ) is measured. Macrophage staining is most frequent at the early recovery phase. There are only minimal macrophages in control rabbits. Error bars indicate $95 \%$ confidence interval. Scale bars: $\boldsymbol{A}, \boldsymbol{B}, 10 \mu \mathrm{m} ; \boldsymbol{C}, 100 \mu \mathrm{m}$.

action potential conduction (Paparounas et al., 1999). A reduction of functioning $\mathrm{Na}_{\mathrm{v}}$ channels results in reduced inward $\mathrm{Na}^{+}$ currents and increased threshold for generation of action potentials. Moreover, paranodal detachment would lead to substantial leakage of driving current and therefore further reduce the safety factor for impulse transmission, presumably resulting in nerve conduction block (Kuwabara et al., 2002). The exposure of juxtaparanodal $\mathrm{Kv}$ channels may also aggravate nerve conduction failure.

\section{Complement activated by anti-GM1 IgG antibodies disrupts nodes of Ranvier}

How do anti-GM1 antibodies induce nodal disruption? It has been suggested that the immune attack directly targets $\mathrm{Na}_{\mathrm{v}}$ channel sugar chains containing sialic acid (Takigawa et al., 1995; Waxman, 1995). However, there is no evidence for this idea. IgG from rabbit Bg-16 did not specifically react to $\mathrm{Na}_{\mathrm{v}}$ channels highly accumulated at the axon initial segments of cultured rat hippocampal neurons (D. P. Schafer and K.S., unpublished observation). Moreover, the intensity of $\mathrm{C} 3$ staining tended to be relatively weak at regions in which some $\mathrm{Na}_{\mathrm{v}}$ channel staining was retained, despite remarkable $\mathrm{C} 3$ deposition at the adjacent axolemma. Gangliosides are an essential component of lipid rafts and may contribute to maintenance of paranodal junctions and ion channel clusters along peripheral motor nerve axons, regardless of their precise localization at and near nodes. Mutant mice with loss of gangliosides including GM1 by the disruption of $\beta 1,4-N$ acetylgalactosaminyltransferase gene have altered paranodal junctions, broadened $\mathrm{Na}_{\mathrm{v}}$ channel clusters, and aberrant $\mathrm{Kv}$ channel localization at the paranodes (Susuki et al., 2007). At the acute phase of the illness in AMAN rabbits, IgG, C3, and MAC depositions were frequently seen at nodes. As in AMAN patients (Hafer-Macko et al., 1996b), complement deposition was most prominent at the acute phase and decreased during recovery. Disruption of $\mathrm{Na}_{\mathrm{v}}$ channel staining was associated with MAC deposition. Without localization of macrophages, nodal components may be altered by complement attack, although the effects of macrophages should be examined at more time points. Thus, the complement-mediated immune pathway by anti-GM1 antibodies plays a crucial role for the initial nodal disruption in the AMAN model.

\section{Disruption of axon-Schwann cell interaction in AMAN model}

How are $\mathrm{Na}_{\mathrm{v}}$ channel clusters disrupted? To answer this question, a better understanding of the mechanisms that stabilize $\mathrm{Na}_{\mathrm{v}}$ channels at the nodal axolemma is required. Paranodal junctions may function as a diffusion barrier to restrict the lateral mobility of ion channels (Bhat et al., 2001; Rios et al., 2003) (supplemental Fig. $3 A$, available at www.jneurosci.org as supplemental material). Consistent with this idea, at abnormally lengthened nodes with MAC formation extending to paranodes, $\mathrm{Na}_{\mathrm{v}}$ channel and Caspr clusters were disrupted. The disruption of paranodal junctions may result in myelin detachment and subsequently remove the diffusion barrier leading to altered $\mathrm{Na}_{\mathrm{v}}$ channel clusters. However, loss of paranodes is not sufficient to disrupt $\mathrm{Na}_{\mathrm{v}}$ channel clusters. Even in mutant mice without paranodal junctions, $\mathrm{Na}_{\mathrm{v}}$ channels still cluster at nodes (Bhat et al., 2001; Rios et al., 2003). Another possible explanation is that both the specialized axonal cytoskeleton and Schwann cell microvilli were disrupted in AMAN rabbits. These structures are required for stabilization of $\mathrm{Na}_{\mathrm{v}}$ channel clusters (Berghs et al., 2000; Komada and Soriano, 2002; Lacas-Gervais et al., 2004; Yang et al., 2004; Eshed et al., 2005; Sherman et al., 2005) (supplemental Fig. 3A, available at www.jneurosci.org as supplemental material). Thus, the disruption of $\mathrm{Na}_{\mathrm{v}}$ channel clusters could be a consequence of destruction of all these structures (supplemental Fig. $3 B$, available at www.jneurosci.org as supplemental material). 

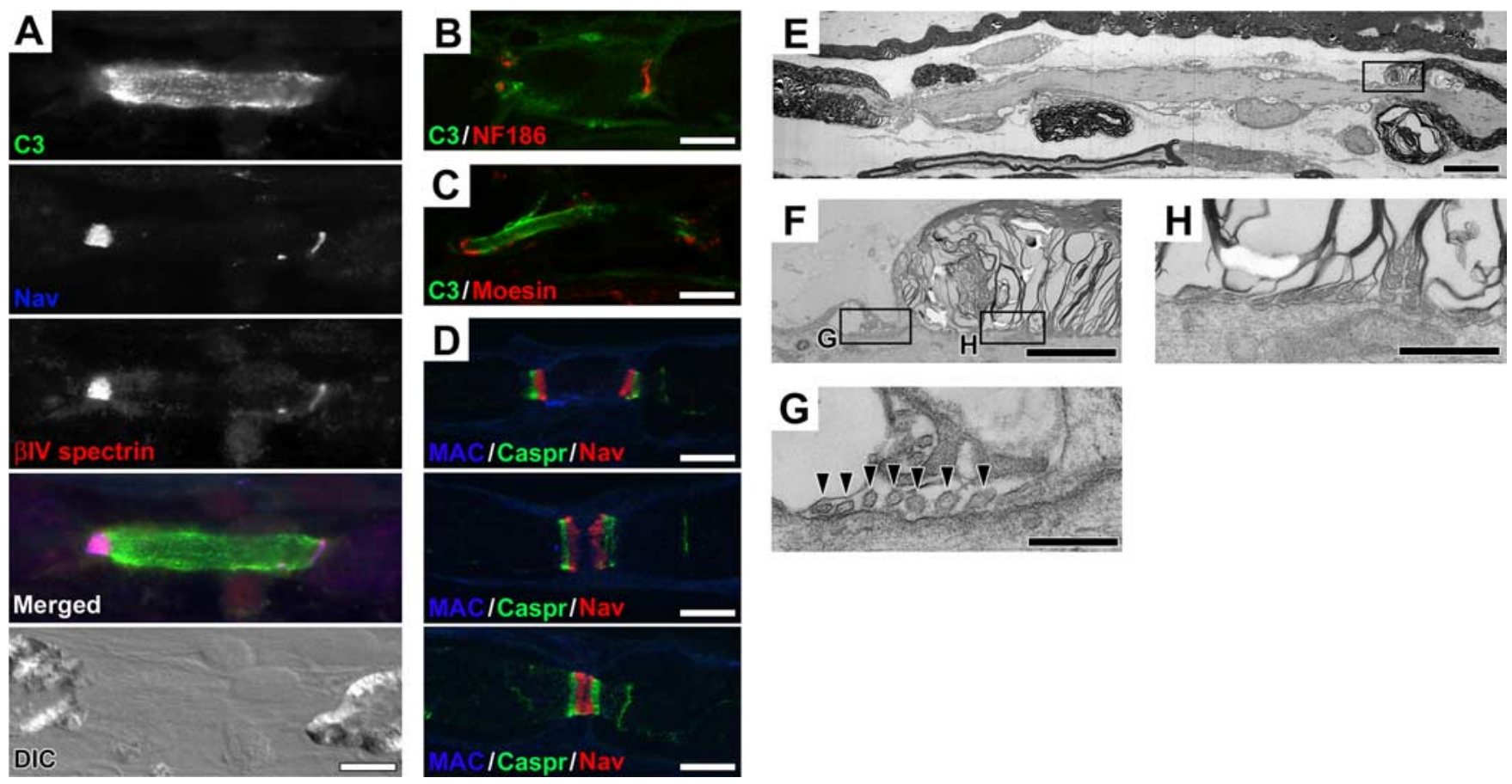

Figure 8. Molecular architectures and structures at and near nodes during recovery phase. $A-D$, Longitudinal sections of ventral roots from rabbits in early $(\boldsymbol{A}-\boldsymbol{C})$ or late $(\boldsymbol{D})$ recovery phases.

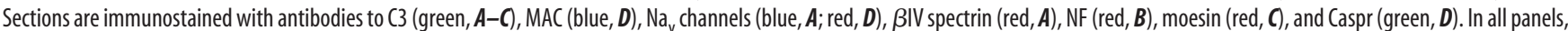
nerve fibers run horizontally. $A, \mathrm{Na}_{\mathrm{v}}$ channels and $\beta \mathrm{IV}$ spectrin aggregate on both sides of lengthened nodes with C3 deposition. $\boldsymbol{B}, \mathrm{NF} 186$ clusters on both sides of affected node. The intensity of $\mathrm{C} 3$

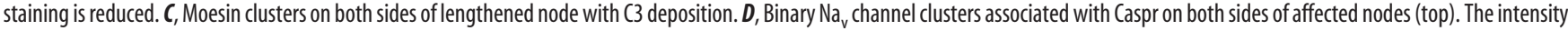
of $\mathrm{MAC}$ staining is reduced. Two adjacent $\mathrm{Na}_{\mathrm{v}}$ channel clusters are present very close (middle) or appear to fuse (bottom). $\boldsymbol{E}$, Electron microscopy showing a remarkably lengthened node in ventral root at the early recovery phase. $\boldsymbol{F}$, Higher magnification of boxed area in $\boldsymbol{E}$. Boxed areas $\boldsymbol{G}$ and $\boldsymbol{H}$ are shown in higher magnification in $\boldsymbol{G}$ and $\boldsymbol{H}$, respectively. $\boldsymbol{G}$, Schwann cell microvilli (arrowheads) on the end of remarkably lengthened node. The finding may be identical to immunofluorescence data depicted on $\boldsymbol{C}$. Note the inside coating of electron-dense material at the axolemma in which microvilli are present, suggestive of the presence of multiprotein complex including $\mathrm{Na}_{\mathrm{v}}$ channels and $\beta \mathrm{IV}$ spectrin. $\boldsymbol{H}$, Paranodal myelin loops noted on the end of remarkably lengthened node. The finding may correspond to immunofluorescence data depicted on $\boldsymbol{D}$. DIC, Differential interference contrast image. Scale bars: $\boldsymbol{A}-\boldsymbol{E}, 10 \mu \mathrm{m} ; \boldsymbol{F}, 2.5 \mu \mathrm{m} ; \boldsymbol{G}, \boldsymbol{H}, 0.5 \mu \mathrm{m}$.

Disruption of $\mathrm{Na}_{\mathrm{v}}$ channel clusters was reported in experimental allergic neuritis, an animal model for AIDP (Novakovic et al., 1998). At the onset of disease in the AIDP model, $\mathrm{Na}_{\mathrm{v}}$ channels became more diffusely distributed into paranodal and juxtaparanodal zones. In contrast, the diffuse $\mathrm{Na}_{\mathrm{v}}$ channel staining along the axon was never seen in the AMAN model. In AMAN, $\mathrm{Na}_{\mathrm{v}}$ channel disruption appears to be more crucially involved in pathophysiology, because primary autoimmune attack occurs directly at the nodal axolemma in which $\mathrm{Na}_{\mathrm{v}}$ channels aggregate at high density (Hafer-Macko et al., 1996b). This is in contrast to AIDP in which the autoimmune target is myelin (Stoll et al., 1991; Hafer-Macko et al., 1996a). Despite different primary lesions, similar alterations of $\mathrm{Na}_{\mathrm{v}}$ channel clusters were observed in both animal models for AMAN and AIDP. That is, $\mathrm{Na}_{\mathrm{v}}$ channels become undetectable during the disease, followed by binary $\mathrm{Na}_{\mathrm{v}}$ channel immunoreactivity and subsequent fusion of these clusters to form new nodes during recovery. Disrupted molecular architecture of the nodal axons is well known in general different peripheral nerve demyelination models. In the lysolecithininduced demyelination model, nodal widening or segmental demyelination is associated with altered $\mathrm{Na}_{\mathrm{v}}$ channels and paranodes at the peak, and two $\mathrm{Na}_{\mathrm{v}}$ channel clusters at heminodes ultimately appear to fuse during remyelination (DugandžijaNovaković et al., 1995; Arroyo et al., 2004; Schafer et al., 2006). Mice with peripheral dysmyelinating or demyelinating phenotypes (e.g., Trembler-J and MPZ-null) display altered paranodes, abnormal $\mathrm{Kv}$ channel distribution, or nodes containing $\mathrm{Na}_{\mathrm{v}} 1.8$ (Ulzheimer et al., 2004; Devaux and Scherer, 2005). Furthermore, retention of $\mathrm{Na}_{\mathrm{v}}$ channel clustering in axons requires the interaction with Schwann cells during development of peripheral myelinated axons (Vabnick et al., 1996; Eshed et al., 2005; Schafer et al., 2006): $\mathrm{Na}_{\mathrm{v}}$ channels initially cluster at heminodes that are associated with myelinating Schwann cells and appear to move toward each other until they fuse and form the condensed cluster. Together, these findings suggest that altered interaction between axons and Schwann cells may be the main cause of pathophysiology in AMAN.

Loss of nodal and paranodal molecules by complement attack The mechanism whereby MAC formation induces loss of nodal and paranodal molecules remains unclear. The MAC inserts itself into target membranes and forms transmembrane pores (Newsholme et al., 1999). MAC insertion may cause axonal membrane instability, resulting in rapid turnover of membrane proteins. Moreover, MAC may enhance $\mathrm{Ca}^{2+}$ influx, leading to irreversible injury (Papadimitriou et al., 1994) or caspase-dependent apoptotic cell death (Fishelson et al., 2001). However, MAC formation does not necessarily lead to cell lysis. For protection from complement attack, nucleated cells eliminate the MAC from their plasma membrane by either ectocytosis (direct emission of membrane vesicles) or exocytosis after endocytosis (Pilzer et al., 2005). If this occurs at the nodes of Ranvier, membrane proteins localized in high densities may be shed together with MAC, resulting in disruption of nodal structures. After successful elimination of MAC, axons survive and interaction with myelinated Schwann cells on both sides of lesions may facilitate redistribution of nodal components to form new nodes of Ranvier. Furthermore, MAC can be neuroprotective during the recovery phase by protecting 
cells from apoptosis (Fishelson et al., 2001; Rus et al., 2005). If the autoimmune attack does not extend further, axonal degeneration can be prevented and nodal function may recover rapidly. This may explain the rapidly reversible nerve conduction failure in human AMAN associated with anti-ganglioside antibodies with a time course that cannot be accounted for by remyelination or axonal regeneration (Kuwabara et al., 1999; Susuki et al., 2001).

A similar pathogenic mechanism has been shown with autoantibodies to gangliosides other than GM1. Anti-GD1a IgG antibodies cause complement-dependent destruction of neuromuscular junctions ex vivo in phrenic nerve-diaphragm preparation from mutant mice that overexpress GD1a (Goodfellow et al., 2005). IgG antibodies to GQ1b ganglioside are believed to be pathogenic in Fisher syndrome, a regional variant of GBS, characterized by acute ophthalmoplegia, ataxia, and areflexia (Overell and Willison, 2005). GQ1b is enriched in presynaptic membranes, and some clinical and experimental evidences suggest that the neuromuscular junction is affected in Fisher syndrome. Recent mouse models have demonstrated that antiGQ1b antibodies activate the classical complement pathway with MAC formation, resulting in severe neuronal and perisynaptic Schwann cell membrane injury (Halstead et al., 2004). In these Fisher syndrome murine models, an inhibitor of complement activation completely prevents MAC formation and thereby has a major neuroprotective effect at the nerve terminal (Halstead et al., 2005). Despite the frequent use of immunomodulating therapies, GBS still carries considerable mortality and residual disability (Hughes and Cornblath, 2005). The modulation of complement pathway during the acute phase might be expected to be an effective therapeutic approach to attenuate the disease process caused by anti-ganglioside antibodies. Increased insight into the pathogenesis of early AMAN will facilitate development of new treatment strategies for autoimmune neuropathies.

\section{References}

Arroyo EJ, Sirkowski EE, Chitale R, Scherer SS (2004) Acute demyelination disrupts the molecular organization of peripheral nervous system nodes. J Comp Neurol 479:424-434.

Berghs S, Aggujaro D, Dirkx Jr R, Maksimova E, Stabach P, Hermel JM, Zhang JP, Philbrick W, Slepnev V, Ort T, Solimena M (2000) BIV spectrin, a new spectrin localized at axon initial segments and nodes of Ranvier in the central and peripheral nervous system. J Cell Biol 151:985-1001.

Bhat MA, Rios JC, Lu Y, Garcia-Fresco GP, Ching W, St. Martin M, Li J, Einheber S, Chesler M, Rosenbluth J, Salzer JL, Bellen HJ (2001) Axonglia interactions and the domain organization of myelinated axons requires neurexin IV/Caspr/Paranodin. Neuron 30:369-383.

Caporale CM, Capasso M, Luciani M, Prencipe V, Creati B, Gandolfi P, De Angelis MV, Di Muzio A, Caporale V, Uncini A (2006) Experimental axonopathy induced by immunization with Campylobacter jejuni lipopolysaccharide from a patient with Guillain-Barré syndrome. J Neuroimmunol 174:12-20.

Comín R, Yuki N, Lopez PHH, Nores GA (2006) High affinity of anti-GM1 antibodies is associated with disease onset in experimental neuropathy. J Neurosci Res 84:1085-1090.

Costigan T (1998) Bonferroni inequalities and intervals. In: Encyclopedia of biostatistics, Vol 1 (Armitage P, Colton T, eds), pp 421-425. New York: Wiley.

Devaux JJ, Scherer SS (2005) Altered ion channels in an animal model of Charcot-Marie-Tooth disease type IA. J Neurosci 25:1470-1480.

Dugandžija-Novaković S, Koszowski AG, Levinson SR, Shrager P (1995) Clustering of $\mathrm{Na}^{+}$channels and node of Ranvier formation in remyelinating axons. J Neurosci 15:492-503.

Einheber S, Zanazzi G, Ching W, Scherer S, Milner TA, Peles E, Salzer JL (1997) The axonal membrane protein Caspr, a homologue of neurexin IV, is a component of the septate-like paranodal junctions that assemble during myelination. J Cell Biol 139:1495-1506.

Eshed Y, Feinberg K, Poliak S, Sabanay H, Sarig-Nadir O, Spiegel I, Berming- ham Jr JR, Peles E (2005) Gliomedin mediates Schwann cell-axon interaction and the molecular assembly of the nodes of Ranvier. Neuron 47:215-229.

Fishelson Z, Attali G, Mevorach D (2001) Complement and apoptosis. Mol Immunol 38:207-219.

Goodfellow JA, Bowes T, Sheikh K, Odaka M, Halstead SK, Humphreys PD, Wagner ER, Yuki N, Furukawa K, Furukawa K, Plomp JJ, Willison HJ (2005) Overexpression of GDla ganglioside sensitizes motor nerve terminals to anti-GDla antibody-mediated injury in a model of acute motor axonal neuropathy. J Neurosci 25:1620-1628.

Griffin JW, Li CY, Macko C, Ho TW, Hsieh ST, Xue P, Wang FA, Cornblath DR, McKhann GM, Asbury AK (1996) Early nodal changes in the acute motor axonal neuropathy pattern of the Guillain-Barré syndrome. J Neurocytol 25:33-51.

Hafer-Macko CE, Sheikh KA, Li CY, Ho TW, Cornblath DR, McKhann GM, Asbury AK, Griffin JW (1996a) Immune attack on the Schwann cell surface in acute inflammatory demyelinating polyneuropathy. Ann Neurol 39:625-635.

Hafer-Macko C, Hsieh ST, Li CY, Ho TW, Sheikh K, Cornblath DR, McKhann GM, Asbury AK, Griffin JW (1996b) Acute motor axonal neuropathy: an antibody-mediated attack on axolemma. Ann Neurol 40:635-644.

Halstead SK, O'Hanlon GM, Humphreys PD, Morrison DB, Morgan BP, Todd AJ, Plomp JJ, Willison HJ (2004) Anti-disialoside antibodies kill perisynaptic Schwann cells and damage motor nerve terminals via membrane attack complex in a murine model of neuropathy. Brain 127:2109-2123.

Halstead SK, Humphreys PD, Goodfellow JA, Wagner ER, Smith RAG, Willison HJ (2005) Complement inhibition abrogates nerve terminal injury in Miller Fisher syndrome. Ann Neurol 58:203-210.

Hirota N, Kaji R, Bostock H, Shindo K, Kawasaki T, Mizutani K, Oka N, Kohara N, Saida T, Kimura J (1997) The physiological effect of antiGM1 antibodies on saltatory conduction and transmembrane currents in single motor axons. Brain 120:2159-2169.

Hughes RAC, Cornblath DR (2005) Guillain-Barré syndrome. Lancet 366:1653-1666

Isbister GK, Kiernan MC (2005) Neurotoxic marine poisoning. Lancet Neurol 4:219-228.

Komada M, Soriano P (2002) $\beta$ IV-spectrin regulates sodium channel clustering through ankyrin-G at axon initial segments and nodes of Ranvier. J Cell Biol 156:337-348.

Kuwabara S, Mori M, Ogawara K, Mizobuchi K, Hattori T, Koga M, Yuki N (1999) Axonal involvement at the common entrapment sites in GuillainBarré syndrome with IgG anti-GM1 antibody. Muscle Nerve 22:840-845.

Kuwabara S, Ogawara K, Sung J-Y, Mori M, Kanai K, Hattori T, Yuki N, Lin CS-Y, Burke D, Bostock H (2002) Differences in membrane properties of axonal and demyelinating Guillain-Barré syndromes. Ann Neurol $52: 180-187$.

Kuwabara S, Bostock H, Ogawara K, Sung J-Y, Kanai K, Mori M, Hattori T, Burke D (2003) The refractory period of transmission is impaired in axonal Guillain-Barré syndrome. Muscle Nerve 28:683-689.

Lacas-Gervais S, Guo J, Strenzke N, Scarfone E, Kolpe M, Jahkel M, De Camilli P, Moser T, Rasband MN, Solimena M (2004) $\beta I V \Sigma 1$ spectrin stabilizes the nodes of Ranvier and axon initial segments. J Cell Biol 166:983-990.

Liang KY, Zeger SL (1986) Longitudinal data analysis using generalized linear models. Biometrika 73:13-22.

Meisler MH, Kearney JA (2005) Sodium channel mutations in epilepsy and other neurological disorders. J Clin Invest 115:2010-2017.

Menegoz M, Gaspar P, Le Bert M, Galvez T, Burgaya F, Palfrey C, Ezan P, Arnos F, Girault J-A (1997) Paranodin, a glycoprotein of neuronal paranodal membranes. Neuron 19:319-331.

Molander M, Berthold CH, Persson H, Andersson K, Fredman P (1997) Monosialoganglioside (GM1) immunofluorescence in rat spinal roots studied with a monoclonal antibody. J Neurocytol 26:101-111.

Newsholme P, Ashford MLJ, Hales CN (1999) Identification of a novel complement-dependent serum-elicited inward current in the Xenopus oocyte provoking $\mathrm{Ca}^{2+}$ influx and subsequent activation of $\mathrm{Cl}^{-}$channels. Biochem Pharmacol 57:491-501.

Nishimoto Y, Koga M, Kamijo M, Hirata K, Yuki N (2004) Immunoglobulin improves a model of acute motor axonal neuropathy by preventing axonal degeneration. Neurology 62:1939-1944. 
Novakovic SD, Levinson SR, Schachner M, Shrager P (1998) Disruption and reorganization of sodium channels in experimental allergic neuritis. Muscle Nerve 21:1019-1032.

Overell JR, Willison HJ (2005) Recent developments in Miller Fisher syndrome and related disorders. Curr Opin Neurol 18:562-566.

Papadimitriou JC, Drachenberg CB, Shin ML, Trump BF (1994) Ultrastructural studies of complement mediated cell death: a biological reaction model to plasma membrane injury. Virchows Arch 424:677-685.

Paparounas K, O’Hanlon GM, O’Leary CP, Rowan EG, Willison HJ (1999) Anti-ganglioside antibodies can bind peripheral nerve nodes of Ranvier and activate the complement cascade without inducing acute conduction block in vitro. Brain 122:807-816.

Peles E, Nativ M, Lustig M, Grumet M, Schilling J, Martinez R, Plowman GD, Schlessinger J (1997) Identification of a novel contactin-associated transmembrane receptor with multiple domains implicated in proteinprotein interactions. EMBO J 16:978-988.

Pilzer D, Gasser O, Moskovich O, Schifferli JA, Fishelson Z (2005) Emission of membrane vesicles: roles in complement resistance, immunity and cancer. Springer Semin Immunopathol 27:375-387.

Poliak S, Peles E (2003) The local differentiation of myelinated axons at nodes of Ranvier. Nat Rev Neurosci 4:968-980.

Rasband MN, Peles E, Trimmer JS, Levinson SR, Lux SE, Shrager P (1999) Dependence of nodal sodium channel clustering on paranodal axoglial contact in the developing CNS. J Neurosci 19:7516-7528.

Rios JC, Rubin M, St. Martin M, Downey RT, Einheber S, Rosenbluth J, Levinson SR, Bhat M, Salzer JL (2003) Paranodal interactions regulate expression of sodium channel subtypes and provide a diffusion barrier for the node of Ranvier. J Neurosci 23:7001-7011.

Rus H, Cudrici C, Niculescu F (2005) C5b-9 complement complex in autoimmune demyelination and multiple sclerosis: dual role in neuroinflammation and neuroprotection. Ann Med 37:97-104.

Schafer DP, Custer AW, Shrager P, Rasband MN (2006) Early events in node of Ranvier formation during myelination and remyelination in the PNS. Neuron Glia Biol 2:69-79.

Scherer SS, Xu T, Crino P, Arroyo EJ, Gutmann DH (2001) Ezrin, radixin, and moesin are components of Schwann cell microvilli. J Neurosci Res 65:150-164.

Sheikh KA, Deerinck TJ, Ellisman MH, Griffin JW (1999) The distribution of ganglioside-like moieties in peripheral nerves. Brain 122:449-460.

Sherman DL, Tait S, Melrose S, Johnson R, Zonta B, Court FA, Macklin WB, Meek S, Smith AJH, Cottrell DF, Brophy PJ (2005) Neurofascins are required to establish axonal domains for saltatory conduction. Neuron 48:737-742.

Stoll G, Schmidt B, Jander S, Toyka KV, Hartung H-P (1991) Presence of the terminal complement complex (C5b-9) precedes myelin degradation in immune-mediated demyelination of the rat peripheral nervous system. Ann Neurol 30:147-155.

Susuki K, Johkura K, Yuki N, Hasegawa O, Kuroiwa Y (2001) Rapid resolution of nerve conduction blocks after plasmapheresis in Guillain-Barré syndrome associated with anti-GM1b IgG antibody. J Neurol 248:148-150.

Susuki K, Nishimoto Y, Yamada M, Baba M, Ueda S, Hirata K, Yuki N (2003) Acute motor axonal neuropathy rabbit model: immune attack on nerve root axons. Ann Neurol 54:383-388.

Susuki K, Nishimoto Y, Koga M, Nagashima T, Mori I, Hirata K, Yuki N (2004) Various immunization protocols for an acute motor axonal neuropathy rabbit model compared. Neurosci Lett 368:63-67.

Susuki K, Baba H, Tohyama K, Kanai K, Kuwabara S, Hirata K, Furukawa K, Furukawa K, Rasband MN, Yuki N (2007) Gangliosides contribute to stability of paranodal junctions and ion channel clusters in myelinated nerve fibers. Glia, in press.

Takigawa T, Yasuda H, Kikkawa R, Shigeta Y, Saida T, Kitasato H (1995) Antibodies against $\mathrm{GM}_{1}$ ganglioside affect $\mathrm{K}^{+}$and $\mathrm{Na}^{+}$currents in isolated rat myelinated nerve fibers. Ann Neurol 37:436-442.

Ulzheimer JC, Peles E, Levinson SR, Martini R (2004) Altered expression of ion channel isoforms at the node of Ranvier in P0-deficient myelin mutants. Mol Cell Neurosci 25:83-94.

Vabnick I, Novaković SD, Levinson SR, Schachner M, Shrager P (1996) The clustering of axonal sodium channels during development of the peripheral nervous system. J Neurosci 16:4914-4922.

van Sorge NM, Yuki N, Jansen MD, Nishimoto Y, Susuki K, Wokke JHJ, van de Winkel JGJ, van den Berg LH, van der Pol W-L (2007) Leukocyte and complement activation by GM1-specific antibodies is associated with acute motor axonal neuropathy in rabbits. J Neuroimmunol 182:116-123.

Waxman SG (1995) Sodium channel blockade by antibodies: a new mechanism of neurological disease? Ann Neurol 37:421-423.

Yang Y, Lacas-Gervais S, Morest DK, Solimena M, Rasband MN (2004) $\beta$ IV spectrins are essential for membrane stability and the molecular organization of nodes of Ranvier. J Neurosci 24:7230-7240.

Yuki N (2005) Carbohydrate mimicry: a new paradigm of autoimmune diseases. Curr Opin Immunol 17:577-582.

Yuki N, Yamada M, Koga M, Odaka M, Susuki K, Tagawa Y, Ueda S, Kasama T, Ohnishi A, Hayashi S, Takahashi H, Kamijo M, Hirata K (2001) Animal model of axonal Guillain-Barré syndrome induced by sensitization with GM1 ganglioside. Ann Neurol 49:712-720.

Yuki N, Susuki K, Koga M, Nishimoto Y, Odaka M, Hirata K, Taguchi K, Miyatake T, Furukawa K, Kobata T, Yamada M (2004) Carbohydrate mimicry between human ganglioside GM1 and Campylobacter jejuni lipooligosaccharide causes Guillain-Barré syndrome. Proc Natl Acad Sci USA 101:11404-11409. 